\title{
Central Amygdala Projections to Lateral Hypothalamus Mediate Avoidance Behavior in Rats
}

\author{
Marcus M. Weera, ${ }^{1}$ Rosetta S. Shackett, ${ }^{1}$ Hannah M. Kramer, ${ }^{1}{ }^{\circledR}$ Jason W. Middleton, ${ }^{2,3,4}$ and \\ (D) Nicholas W. Gilpin ${ }^{1,3,4,5}$ \\ ${ }^{1}$ Department of Physiology, School of Medicine, Louisiana State University Health Sciences Center, New Orleans, Louisiana $70112,{ }^{2}$ Department of \\ Cell Biology, School of Medicine, Louisiana State University Health Sciences Center, New Orleans, Louisiana 70112 , ${ }^{3}$ Neuroscience Center of \\ Excellence, Louisiana State University Health Sciences Center, New Orleans, Louisiana 70112, ${ }^{4}$ Alcohol and Drug Abuse Center of Excellence, \\ Louisiana State University Health Sciences Center, New Orleans, Louisiana 70112, and ${ }^{5}$ Southeast Louisiana VA Healthcare System (SLVHCS), \\ New Orleans, Louisiana 70119
}

Persistent avoidance of stress-related stimuli following acute stress exposure predicts negative outcomes such as substance abuse and traumatic stress disorders. Previous work using a rat model showed that the central amygdala (CeA) plays an important role in avoidance of a predator odor stress-paired context. Here, we show that CeA projections to the lateral hypothalamus (LH) are preferentially activated in male rats that show avoidance of a predator odor-paired context (termed Avoider rats), that chemogenetic inhibition of CeA-LH projections attenuates avoidance in male Avoider rats, that chemogenetic stimulation of the CeA-LH circuit produces conditioned place avoidance (CPA) in otherwise naive male rats, and that avoidance behavior is associated with intrinsic properties of $\mathrm{LH}$-projecting CeA cells. Collectively, these data show that CeALH projections are important for persistent avoidance of stress-related stimuli following acute stress exposure.

Key words: avoidance; central amygdala; HCN channels; lateral hypothalamus; stress

\section{Significance Statement}

This study in rats shows that a specific circuit in the brain [i.e., neurons that project from the central amygdala (CeA) to the lateral hypothalamus (LH)] mediates avoidance of stress-associated stimuli. In addition, this study shows that intrinsic physiological properties of cells in this brain circuit are associated with avoidance of stress-associated stimuli. Further characterization of the CeA-LH circuit may improve our understanding of the neural mechanisms underlying specific aspects of stress-related disorders in humans.

\section{Introduction}

Exposure to stressful events often leads to adverse consequences such as increased anxiety, depression, and negative changes in cognition and mood. The type of coping mechanism engaged during stress exposure predicts the severity of stress-related consequences (Moos and Schaefer, 1993). Avoidance coping mechanisms are associated with negative consequences such as suicide (Linehan et al., 1986) and engaging in violence (Kotler et al.,

Received Jan. 30, 2020; revised 0ct. 26, 2020; accepted 0ct. 28, 2020.

Author contributions: M.M.W., J.W.M., and N.W.G. designed research; M.M.W., R.S.S., H.M.K., and J.W.M. performed research; M.M.W. and J.W.M. analyzed data; M.M.W. wrote the paper.

This work was supported by National Institutes of Health Grants AA023305 (to N.W.G.), AA026531 (to N.W.G.), AA026022 (to N.W.G.), AA027145 (to M.M.W.), and AA007577. This work was also supported in part by a Merit Review Award \#101 BX003451 (to N.W.G.) from the United States Department of Veterans Affairs, Biomedical Laboratory Research and Development Service.

N.W.G. owns shares in Glauser Life Sciences, Inc., a company with interest in developing therapeutics for mental health disorders, and there was no direct link between those interests and the work contained here. All other authors declare no competing financial interests.

Correspondence should be addressed to Marcus M. Weera at mweera@|suhsc.edu.

https://doi.org/10.1523/JNEUROSCI.0236-20.2020

Copyright $\odot 2021$ the authors
1993), as well as substance abuse (Mezzich et al., 1995) and posttraumatic stress disorder (PTSD; Bryant and Harvey, 1995). Among PTSD patients, persistent avoidance of stress-associated stimuli is a strong predictor of poor treatment response (Taylor et al., 2001) and future PTSD severity (Bryant et al., 2000; Perkonigg et al., 2005; Shin et al., 2015).

The use of animal models to investigate the neurobiological factors underlying stress effects is critical for the development of better prevention, diagnostic, and treatment strategies. Our laboratory uses a model in which a subset of rats exposed to predator odor stress show persistent and stable avoidance of odor-paired stimuli (context with distinct tactile and visual cues), mirroring avoidance symptoms in some but not all humans exposed to stress (Breslau, 2009; Albrechet-Souza and Gilpin, 2019). After stress, rats classified as Avoiders exhibit hyperalgesia (Itoga et al., 2016), escalated alcohol drinking, more aversion-resistant alcohol responding (Edwards et al., 2013; Weera et al., 2020), higher anxiety-like behavior than unstressed controls (Whitaker and Gilpin, 2015), and blunted corticosterone response to predator odor relative to Non-Avoiders exposed to the same stress 
(Whitaker and Gilpin, 2015). These effects are not attributable to non-specific factors such as learning or animals' ability to detect the predator odor stimulus. For example, we have shown that conditioned preference for a context paired with sweet solution does not predict conditioned avoidance of a context paired with predator odor (i.e., bobcat urine; Edwards et al., 2013), and that predator odor stress exposure increases adrenocorticotropin hormone and corticosterone levels in both Avoiders and NonAvoiders (Whitaker and Gilpin, 2015).

In humans with PTSD, amygdala hyperreactivity predicts the magnitude of avoidance (Sripada et al., 2013) and the severity of overall PTSD symptoms (Stevens et al., 2017). In rats, the central amygdala (CeA) serves as the main output nucleus of the amygdala and is an important modulator of behavioral and physiological stress responses (Ventura-Silva et al., 2013). Previous findings in our lab suggest that $\mathrm{CeA}$ is an important node for mediating avoidance of aversive stimuli and other behaviors in Avoider rats. For example, male Avoider rats show escalated corticotropin-releasing factor (CRF) peptide content in CeA after stress compared with Non-Avoiders and unstressed Controls, intra-CeA infusions of CRF produce avoidance in stress-naive male rats (Itoga et al., 2016), and intra-CeA blockade of CRF1 receptors (CRFR1) attenuates stress-induced avoidance behavior, escalated alcohol drinking (Weera et al., 2020), and hyperalgesia in male Avoider rats (Itoga et al., 2016).

CeA cells project to several downstream effector brain regions, including the lateral hypothalamus ( $\mathrm{LH}$; Krettek and Price, 1978; Tsumori et al., 2006). The LH plays an important role in modulating motivated behaviors, including approach and avoidance (Stuber and Wise, 2016). For example, activation of LH GABAergic cells produces real-time place preference (Jennings et al., 2015), whereas activation of LH glutamatergic cells produces real-time place aversion (Jennings et al., 2013). Interestingly, a recent study in mice showed that predator odor exposure increased $\mathrm{Ca}^{2+}$-indicated activity in $\mathrm{LH}$ hypocretin-expressing ( $\mathrm{Hcrt}+$ ) cells and that chemogenetic stimulation of these cells produced real-time place avoidance (Giardino et al., 2018).

Here, we tested the hypotheses that predator odor exposure activates CeA projections to $\mathrm{LH}(\mathrm{CeA}-\mathrm{LH})$ in Avoiders, that inhibition of CeA-LH projections attenuates avoidance behavior in Avoiders, and that CeA-LH circuit stimulation supports the development of conditioned place avoidance (CPA) behavior in otherwise naive animals. We also characterized the topographical and physiological properties of these projections at baseline and after predator odor exposure. Findings from this study lay the foundation for future work that will interrogate the role of CeALH signaling in other stress-related behaviors (e.g., altered alcohol/drug reward and aversion).

\section{Materials and Methods}

\section{Subjects}

Adult male Wistar rats (Charles River) were used in all experiments. Rats were pair-housed in a humidity-controlled and temperature-controlled $\left(22^{\circ} \mathrm{C}\right)$ vivarium on a reverse $12 / 12 \mathrm{~h}$ light/dark cycle (lights off at 8:00 A.M.) and had ad libitum access to food and water. All behavioral procedures occurred in the dark phase under red or dim light illumination. All procedures were approved by the Institutional Animal Care and Use Committee of the Louisiana State University Health Science Center and were in accordance with National Institutes of Health guidelines.

\section{Drugs}

Clozapine-N-oxide (CNO; NIH Drug Supply Program) was dissolved in 20\% dimethylsulfoxide (DMSO). ZD7288 (Tocris, catalog \#1000) was dissolved in DI water for a stock concentration of $8 \mathrm{~mm}$. ZD7288 stock was diluted $400 \times$ when added to the recording bath artificial CSF (aCSF) for a final concentration of $20 \mu \mathrm{M}$. Capsazepine (Sigma-Aldrich, catalog \#C191) was dissolved in 45\% DMSO/55\% DI water for a stock concentration of $12 \mathrm{~mm}$. Capsazepine stock was diluted $400 \times$ when added to the recording bath aCSF for a final concentration of $30 \mu \mathrm{M}$. Tetrodotoxin (TTX)-citrate (Tocris, catalog \#1069) was dissolve in DI water for a stock concentration $0.4 \mathrm{~mm}$ and dissolved to a final concentration of $1 \mu \mathrm{M}$ in the recording aCSF bath. 4-Aminopyridine (4AP; Tocris, catalog \#0940) was dissolve in DI water for a stock concentration $0.4 \mathrm{M}$ and dissolved to a final concentration of $1 \mathrm{~mm}$ in the recording aCSF bath.

\section{Stereotaxic surgeries}

Rats were anesthetized with isoflurane and mounted into a stereotaxic frame (Kopf Instruments) for all stereotaxic surgeries. The following coordinates (from bregma) were used for bilateral intra-LH or CeA microinjections: $-2.1 \mathrm{~mm}$ posterior, $\pm 2.0 \mathrm{~mm}$ lateral, and $-8.8 \mathrm{~mm}$ ventral $(\mathrm{LH})$ or $-2.5 \mathrm{~mm}$ posterior, $\pm 4.0 \mathrm{~mm}$ lateral, and $-8.4 \mathrm{~mm}$ ventral (CeA). Retrobeads (Lumafluor), Cholera Toxin B (Thermo Fisher Scientific, catalog \#22843), or viral constructs (see below) were injected into each side of the $\mathrm{LH}$ or CeA at a volume of $0.5 \mu \mathrm{l}$ over $5 \mathrm{~min}$, and injectors were left in place for an additional $2 \mathrm{~min}$. Viral titers were between 1.0 and $1.5 \times 1013 \mathrm{GC} / \mathrm{ml}$. At the end of surgeries, rats were monitored to ensure recovery from anesthesia and were given at least $6 \mathrm{~d}$ to recover before the start of behavioral procedures. Rats were treated with the analgesic flunixin $(2.5 \mathrm{mg} / \mathrm{kg}$, s.c. $)$ and the antibiotic cefazolin $(20 \mathrm{mg} / \mathrm{kg}$, i.m.) before the start of surgeries and once the following day.

\section{Predator odor place conditioning}

Predator odor place conditioning was performed as previously described (Edwards et al., 2013; Albrechet-Souza and Gilpin, 2019). The apparatus consists of three conditioning chambers with distinct tactile (hole, grid, or rod floors) and visual stimuli (circles, white, or stripes walls) separated by a small triangular center chamber. On day 1 , rats were allowed to freely explore the apparatus for $5 \mathrm{~min}$, and the chamber with the most deviant time score for each rat was excluded from future sessions. On day 2 , rats were allowed to freely explore the two-chamber apparatus for 5 min (without the excluded chamber) and time spent in each chamber was recorded as preconditioning baseline (CPA pretest time). Rats were assigned to Stress or Unstressed Control groups, counterbalanced for the magnitude of baseline preference for the conditioning chambers. Rats in the stress group received predator odor place conditioning in an unbiased and counterbalanced design. On day 3 , rats were confined to one chamber for $15 \mathrm{~min}$ in the absence of odor. On day 4 , rats were confined to the other chamber for $15 \mathrm{~min}$ in the presence of predator odor (a sponge soaked with $3 \mathrm{ml}$ of bobcat urine; Maine Outdoor Solutions) placed under the floor. On day 5 , rats were again allowed to freely explore the 2 conditioning chambers for $5 \mathrm{~min}$ and time spent in each chamber was recorded (CPA posttest time). Time spent in the odorpaired chamber during CPA posttest minus pretest was used to index for avoidance. Rats that showed greater than a 10-s decrease in time spent on the odor-paired chamber were classified as Avoiders and all other stressed rats were classified as Non-Avoiders. Unstressed Controls were never exposed to predator odor.

\section{Immunohistochemistry}

Rats were deeply anesthetized with isoflurane and were transcardially perfused with ice-cold PBS followed by $4 \%$ paraformaldehyde (PFA). Brains were extracted and postfixed in $4 \%$ PFA for $24 \mathrm{~h} \mathrm{(at} 4^{\circ} \mathrm{C}$ ), cryoprotected in $20 \%$ sucrose for $48-72 \mathrm{~h}$ (at $4^{\circ} \mathrm{C}$ ), and snap-frozen in 2 -methylbutane on dry ice. Forty-micrometer coronal sections were collected using a cryostat and stored in $0.1 \%$ sodium azide in PBS at $4^{\circ} \mathrm{C}$. Sections were washed $2 \times 10 \mathrm{~min}$ in PBS and incubated in $3 \%$ hydrogen peroxide for $10 \mathrm{~min}$. Sections were then washed $3 \times 10 \mathrm{~min}$ in PBS and incubated in a blocking buffer containing $1 \%(\mathrm{w} / \mathrm{v})$ bovine serum albumin and $0.3 \%$ Triton X-100 in PBS for $1 \mathrm{~h}$ at room temperature (RT). Then, sections were incubated in a rabbit anti-c-Fos antibody (Millipore; catalog \#ABE457, RRID:AB_2631318) for $48 \mathrm{~h}$ at $4^{\circ} \mathrm{C}$. Sections were 
then washed for $10 \mathrm{~min}$ in TNT buffer $(0.1 \mathrm{~m}$ Tris base in saline with $0.3 \%$ Triton X-100), incubated for $30 \mathrm{~min}$ in $0.5 \%(\mathrm{w} / \mathrm{v})$ tyramide signal amplification (TSA) blocking reagent (see below) in $0.1 \mathrm{M}$ Tris base, and incubated for $30 \mathrm{~min}$ in ImmPRESS horseradish peroxidase anti-rabbit antibody (Vector Laboratories, catalog \#MP-7401; RRID:AB_2336529) at RT. Following $4 \times 5 \mathrm{~min}$ washes in TNT buffer, sections were incubated in cyanine 3 for $10 \mathrm{~min}$ at RT (TSA blocking reagent and cyanine 3 were part of the TSA Cyanine 3 detection kit; PerkinElmer, catalog \#NEL704A001KT). Sections were washed $3 \times 10 \mathrm{~min}$ in TNT buffer and mounted on microscope slides with Fluoro-Gel II with DAPI (Electron Microscopy Sciences, catalog \#17985-51).

\section{Slice electrophysiology}

On the day of slice electrophysiology experiments, rats were deeply anesthetized with isoflurane and transcardially perfused with $80-\mathrm{ml} \mathrm{RT}$ $\left(\sim 25^{\circ} \mathrm{C}\right)$ NMDG aCSF containing the following: $92 \mathrm{~mm}$ NMDG, $2.5 \mathrm{~mm}$ $\mathrm{KCl}, 1.25 \mathrm{~mm} \mathrm{NaH}_{2} \mathrm{PO}_{4}, 30 \mathrm{~mm} \mathrm{NaHCO}, 20 \mathrm{~mm}$ HEPES, $25 \mathrm{~mm}$ glucose, $2 \mathrm{~mm}$ thiourea, $0.5 \mathrm{~mm} \mathrm{CaCl}_{2}, 10 \mathrm{~mm} \mathrm{MgSO}_{4} \cdot 7 \mathrm{H}_{2} \mathrm{O}, 5 \mathrm{~mm} \mathrm{Na}$ ascorbate, and $3 \mathrm{~mm} \mathrm{Na-} \mathrm{pyruvate;} 300-\mu \mathrm{m}$-thick coronal sections containing the CeA were collected using a vibratome (VT1200S, Leica Microsystems). Sections were incubated in NMDG aCSF at $36^{\circ} \mathrm{C}$ for $12 \mathrm{~min}$, then transferred to a RT holding aCSF solution containing the following: $92 \mathrm{~mm} \mathrm{NaCl}, 2.5 \mathrm{~mm} \mathrm{KCl}, 1.25 \mathrm{~mm} \mathrm{NaH}_{2} \mathrm{PO}_{4}, 30 \mathrm{~mm}$ $\mathrm{NaHCO}_{3}, 20$ mм HEPES, 25 mм glucose, $2 \mathrm{~mm}$ thiourea, $2 \mathrm{~mm} \mathrm{CaCl}$, 2 $\mathrm{mm} \mathrm{MgSO}_{4} \cdot 7 \mathrm{H}_{2} \mathrm{O}, 5 \mathrm{~mm} \mathrm{Na}$-ascorbate, and $3 \mathrm{~mm} \mathrm{Na}$-pyruvate. Brain sections were allowed to rest $\geq 1 \mathrm{~h}$ before commencement of the recording session. At the time of recording sections were transferred to a recording aCSF solution containing the following: $130 \mathrm{~mm} \mathrm{NaCl}, 3.5 \mathrm{~mm}$ $\mathrm{KCl}, 2 \mathrm{~mm} \mathrm{CaCl}, 1.25 \mathrm{~mm} \mathrm{NaH}_{2} \mathrm{PO}_{4}, 1.5 \mathrm{~mm} \mathrm{MgSO} \cdot 7 \mathrm{H}_{2} \mathrm{O}, 24 \mathrm{~mm}$ $\mathrm{NaHCO}_{3}$, and $10 \mathrm{~mm}$ glucose (Avegno et al., 2018). Recording aCSF was maintained at $31-33^{\circ} \mathrm{C}$ using an in-line heater (Warner Instruments). Recordings were performed with an internal recording solution containing the following: $120 \mathrm{~mm}$ K-gluconate, $4 \mathrm{~mm} \mathrm{KCl,} 2 \mathrm{~mm} \mathrm{~K}$-EGTA, 10 mM HEPES, 4 mм Mg-ATP, $0.3 \mathrm{~mm} \mathrm{Na}_{2}$-GTP, and $10 \mathrm{~mm} \mathrm{Na}_{2}$-phosphocreatine; pH 7.2-7.3 (285-295 mOsm; Mayeux et al., 2017; Avegno et al., 2018).

\section{In situ hybridization}

RNAscope in situ hybridization was performed following the manufacturer's recommendations. Rats were perfused transcardially, and brains were fixed and frozen as described above (see above, Immunohistochemistry). Ten-micrometer coronal sections were collected using a cryostat and stored in $0.1 \%$ sodium azide in PBS at $4^{\circ} \mathrm{C}$. Sections were washed $2 \times 10 \mathrm{~min}$ in PBS and incubated in TBS-T containing 3\% hydrogen peroxide for $20 \mathrm{~min}$. Sections were then washed $2 \times 10 \mathrm{~min}$ in $\mathrm{PBS}$ and float mounted onto microscope slides, allowed to dry overnight, and stored in $100 \%$ ethanol at $-20^{\circ} \mathrm{C}$ for up to one week. For RNAscope processing, slides were removed from ethanol, air dried, and a hydrophobic barrier was drawn around each brain section. Brain sections were covered with Protease III and incubated at $40^{\circ} \mathrm{C}$ for $45 \mathrm{~min}$. Sections were then washed in PBS $2 \times 2 \mathrm{~min}$, covered with a $C r h r 1$ RNA probe (Advanced Cell Diagnostics, Rn-Crhr1, catalog \#318911-C3), and incubated at $40^{\circ} \mathrm{C}$ for $4 \mathrm{~h}$. Sections were then incubated for $15 \mathrm{~min}$ in $5 \times$ saline-sodium citrate buffer at RT and washed $2 \times 2 \mathrm{~min}$ in RNAscope Wash buffer. Sections were then incubated consecutively with RNAscope AMP 1 (40 min), AMP 2 (20 min), AMP 3 (40 min), and AMP 4A (20 min) reagents at $40^{\circ} \mathrm{C}$, with $2 \times 2 \mathrm{~min}$ washes in RNAscope Wash buffer in between each incubation. Sections were then coverslipped with Fluoro-Gel II with DAPI (Electron Microscopy Sciences, catalog \#17985-51). All RNAscope probes, reagents, and buffers were purchased from Advanced Cell Diagnostics (RNAscope Fluorescent Multiplex kit, reference \#320851).

\section{Experiment 1}

The purpose of this experiment was to map CeA-LH projections using anterograde and retrograde tracing and to test synaptic connections between CeA projections and LH cells using a combination of optogenetics and slice electrophysiology.
CeA-LH anterograde and retrograde tracing

For anterograde tracing, rats $(n=3)$ were given bilateral microinjections of AAV5-hSyn-mCherry (Addgene, 114472-AAV5) and were killed four weeks later (Fig. $1 A$ ). For CeA-LH retrograde tracing, rats $(n=24)$ were given bilateral Retrobeads microinjections targeting the LH (see above, Stereotaxic surgeries) at least $12 \mathrm{~d}$ before killing. These animals were also used in the c-Fos experiment (experiment 2) (Fig. 1F).

\section{CeA-LH slice electrophysiology with optogenetics}

Rats were given intra-CeA AAV5-hSyn-hChR2(h134R)-mCherry (Addgene; 26976-AAV5) at least four weeks before killing and slice electrophysiology. Voltage-clamp recordings were performed with cells clamped at $-50 \mathrm{mV}$. Light pulses $\left(\sim 13 \mathrm{~mW} / \mathrm{mm}^{2}\right.$ power density, $0.5-\mathrm{ms}$ pulse duration, $10-\mathrm{Hz}$ frequency) were delivered and IPSC responses were measured. In a subset of recorded neurons, after characterizing baseline IPSC amplitude, picrotoxin (PTX; $100 \mu \mathrm{M}$ ) was applied to the bath and postsynaptic response to optical stimulation was measured 15 min later. In another set of neurons, optically evoked responses in $\mathrm{LH}$ were recorded in the presence of the sodium channel blocker TTX (1 $\mu \mathrm{M})$ and the potassium channel blocker 4AP $(1 \mathrm{~mm})$. Either: (1) wholecell recording was established first, synaptic responses were measured, then TTX and 4AP were added to the bath and responses were remeasured in the same neuron; or (2) TTX and 4AP was circulating in the bath before whole-cell recording was established and then responses were measured only in the presence of TTX and 4AP.

\section{Experiment 2}

The purpose of this experiment was to test the hypothesis that predator odor stress produces more neuronal activation (c-Fos + ) in CeA-LH cells in Avoiders relative to stressed Non-Avoiders and unstressed Controls. Rats were given intra-LH injections of Retrobeads and were subjected to the predator odor place conditioning procedure described above (after at least $6 \mathrm{~d}$ of recovery from surgery). On the day after CPA posttest, rats were re-exposed to predator odor in a clean cage for $15 \mathrm{~min}$ (a cup containing a bobcat urine-soaked sponge was placed on top of the cage) and were killed $90 \mathrm{~min}$ later (Fig. $2 A$ ). Brain sections were analyzed for accuracy of Retrobeads microinjections. Three rats were removed from analysis because of misplaced Retrobeads microinjections and two rats were removed because of procedural error during predator odor place conditioning (final $n=19$ ). Three $40-\mu \mathrm{m}$ brain sections separated by $\sim 200 \mu \mathrm{m}$ were processed for c-Fos immunohistochemistry and analyzed. Retrobeads + and c-Fos + cell counts were calculated for whole CeA, medial CeA $(\mathrm{CeM})$ and lateral $\mathrm{CeA}(\mathrm{CeL})$ across three brain sections (Fig. $1 G$ for anatomic outline of CeM vs CeL). c-Fos activation in CeALH cells was expressed as the percentage of total Retrobeads + cells that were c-Fos +/Retrobeads + (i.e., c-Fos and Retrobeads double positive).

\section{Experiment 3}

The purpose of this experiment was to test the hypothesis that the CeALH circuit mediates conditioned avoidance behavior. Specifically, we tested the hypotheses that inhibition of CeA-LH cells attenuates conditioned avoidance of a predator odor stress-paired chamber in Avoider rats and that stimulation of CeA-LH cells supports the development of $\mathrm{CPA}$ in stress-naive rats.

\section{CeA-LH circuit inhibition}

To test the hypothesis that inhibition of CeA-LH cells attenuates avoidance behavior in Avoider rats, inhibitory designer receptors exclusively activated by designer drugs (DREADD) receptor-containing virus or mCherry control virus was targeted to CeA-LH cells using an intersectional viral expression strategy. Rats $(n=64)$ were given bilateral microinjections of a retrograde viral vector for the expression of Cre (AAVrg-pmSyn1-EBFP-Cre; Addgene, 51507-AAVrg) targeting the LH. Two weeks later, half of the rats $(n=32)$ were given bilateral intra-CeA microinjections of a viral vector for Cre-dependent expression of an inhibitory DREADD receptor (AAV5-hSyn-DIO-hM4D(Gi)-mCherry; Addgene 44362-AAV5), and the other half of the rats $(n=32)$ were given bilateral intra-CeA microinjections of a control viral vector (AAV5-hSyn-DIO-mCherry, Addgene, 50459-AAV5; Fig. 3A,B). Four 
A

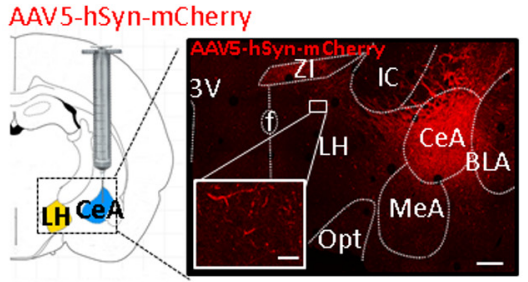

B

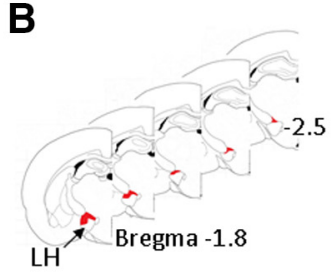

C

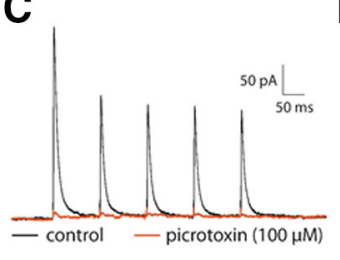

D

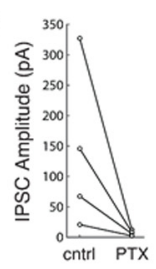

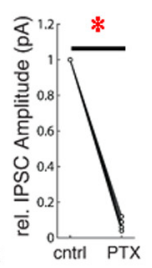

E

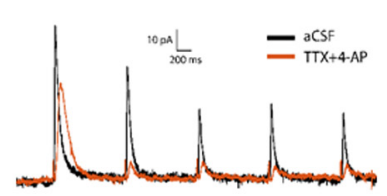

F

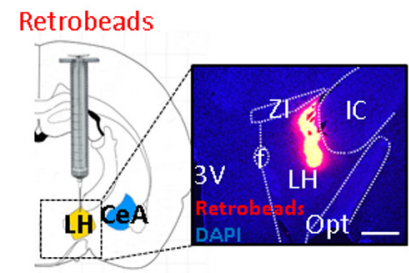

G

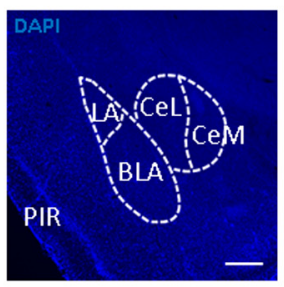

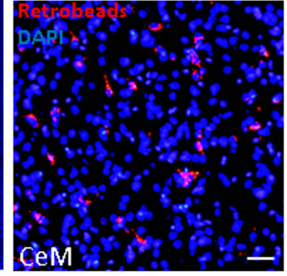

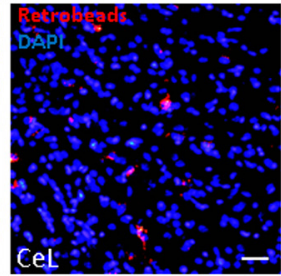

H

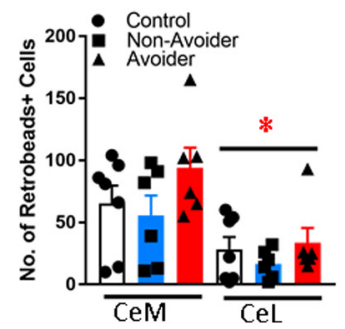

I

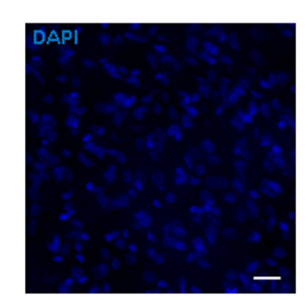

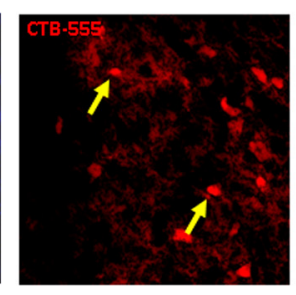
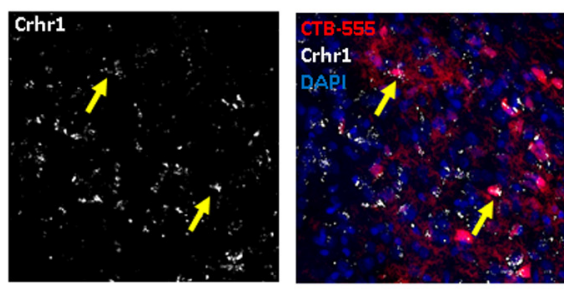

Figure 1. CeA projections form functional connections with LH neurons. A, Schematic of intra-CeA microinjections of AAV5-hSyn-mCherry. Right, Image showing mCherry expression in a coronal brain section containing the CeA and LH (scale bar: $500 \mu \mathrm{m}$ ). Inset, High-magnification image of mCherry fibers in LH (scale bar: $20 \mu \mathrm{m})$. $3 \mathrm{~V}$ : third ventricle, f: fornix, Zl: zona incerta, LH: lateral hypothalamus, Opt: optic tract, IC: internal capsule, MeA: medial amygdala, CeA: central amygdala, BLA: basolateral amygdala. B, Schematic showing approximate location of mCherry + terminals (red) in LH along the rostro-caudal axis. C, Representative trace showing optically evoked current of LH neuron in the absence (black) and presence (orange) of the GABAA receptor blocker PTX. D, In neurons that received PTX, relative synaptic response amplitudes were significantly decreased $(* p<0.001)$. $\boldsymbol{E}$, An example recording of postsynaptic current in an LH neuron showing response to optical stimulation of (eA neuron axon terminals before and after bath application of TTX and 4AP. $F$, Schematic of intra-LH microinjections of Retrobeads. Right, Representative image of intra-LH Retrobeads microinjection site (scale bar: $200 \mu \mathrm{m})$. G, left, Low-magnification ( $2 \times$ ) image showing medial (CeM) and lateral (CeL) subdivisions of CeA and surrounding landmarks. LA: lateral amygdala, BLA: basolateral amygdala, PIR: piriform cortex. Middle and right, Representative images of Retrobeads + cells in CeM versus CeL (scale bar: $50 \mu \mathrm{m}) . \boldsymbol{H}$, Retrobeads + cell counts in CeM versus (eL of Avoider, Non-Avoider, and Controls rats ( $* p<0.001 ; n=6$ or 7 rats per group). $\boldsymbol{I}$, Expression of (rhr 1 in CeA-LH projection cells (labeled with (TB-555; scale bar: $50 \mu \mathrm{m}$ ). Arrows indicate examples of double-labeled cells.

weeks later, rats underwent the predator odor place conditioning procedure described above. One day after posttest ("test 1," in which rats were indexed for avoidance of the predator odor-paired chamber), rats were given a second posttest session ("test 2") that was preceded by a $30 \mathrm{~min}$ $\mathrm{CNO}(4 \mathrm{mg} / \mathrm{kg})$ or vehicle (20\% DMSO in saline) pretreatment $(1 \mathrm{ml} / \mathrm{kg}$ body weight, i.p.; Fig. $3 C$ ). Change in time spent in the predator odorpaired chamber from test 1 to test 2 was used as an index of change in avoidance behavior.

\section{CeA-LH circuit stimulation}

To test the hypothesis that stimulation of CeA-LH cells supports conditioned avoidance behavior in stress-naive rats, stimulatory DREADD receptor-containing virus (AAV5-hSyn-DIO-hM3D(Gq)-mCherry; Addgene, 44 361-AAV5) or mCherry control virus was targeted to CeA-LH cells using the same intersectional viral strategy described above. Place conditioning procedures began no fewer than $14 \mathrm{~d}$ after CeA virus microinjections. The conditioning apparatus is identical to the one used for predator odor place conditioning described above. On the day before the start of CPA procedures, rats were handled and weighed in the procedure room. On day 1 , rats were given vehicle (20\% DMSO in saline; i.p.) injections $(1 \mathrm{ml} / \mathrm{kg}) \mathrm{im}$ mediately before they were placed in the conditioning apparatus and allowed to freely explore all three chambers for $5 \mathrm{~min}$. As with predator odor place conditioning, the chamber with the most deviant time score for each animal was removed from all future procedures for that particular rat. On day 2, this procedure was repeated with two chambers and time spent in each conditioning chamber was recorded as preconditioning baseline (pretest time). On day 3 , rats were given vehicle injection ( $1 \mathrm{ml} / \mathrm{kg}$, i.p.) immediately before confinement to one conditioning chamber for $15 \mathrm{~min}$. On day 4, rats were given a CNO injection of 0,2 , or $4 \mathrm{mg} / \mathrm{kg}(1 \mathrm{ml} / \mathrm{kg}$, i.p. $)$ immediately before confinement to the other chamber for $15 \mathrm{~min}$. On day 5 , rats were given vehicle injection immediately before they were allowed to freely explore both chambers for $5 \mathrm{~min}$ (posttest 1), and a difference score of time spent in the CNO-paired chamber during posttest minus pretest was calculated. This 5 - $\mathrm{d}$ chemogenetic place conditioning procedure is identical to the 5-d predator odor place conditioning procedure used above. Time spent in the CNO-paired chamber during test 1 minus pretest was analyzed to test whether a single CeA-LH circuit stimulation session can produce CPA. After a 2-d break (Saturday and Sunday), rats were given additional conditioning sessions to test the effect of repeated CeA-LH circuit stimulation on avoidance behavior. Rats were given two vehicle (Monday and Wednesday) and two CNO (Tuesday and Thursday) conditioning sessions followed by a second posttest (Friday). This procedure was repeated a third time in week 3. In total, rats received five CNO conditioning sessions, five vehicle conditioning sessions, and three posttests (Fig. $3 E$ ). Each rat was always injected with the same dose of CNO (i.e., between-subjects dose response) or an equivalent volume of vehicle. Rats were weighed immediately before each injection. The conditioning score for each posttest was calculated by subtracting pretest time spent in $\mathrm{CNO}$-paired chamber from posttest time spent in $\mathrm{CNO}$-paired chamber. Positive values were interpreted to reflect a preference for the CNO-paired chamber; negative values were interpreted to reflect an aversion for the CNO-paired chamber.

At the end of the experiment, all rats were killed, and brains were imaged to ensure accuracy of virus expression as indicated by mCherry+ cell bodies. One and four rats were removed from the DREADD inhibition and stimulation studies, respectively, because of inaccurate virus expression outside the CeA. 
A

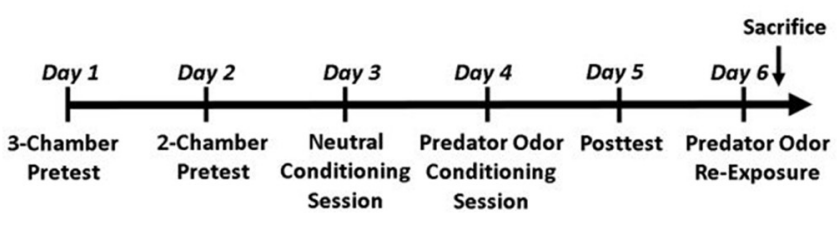

C
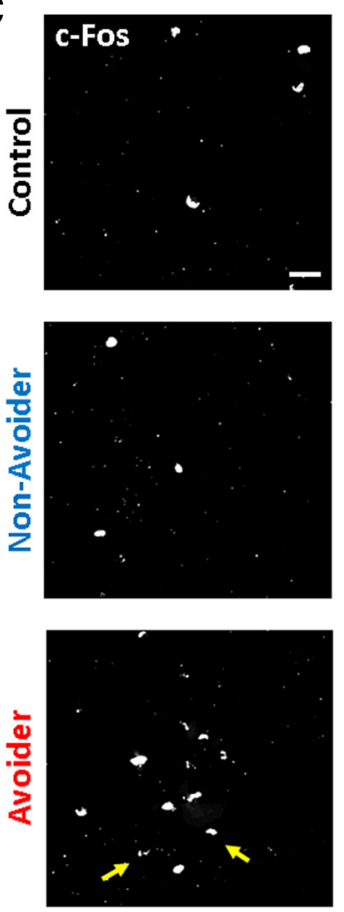

D

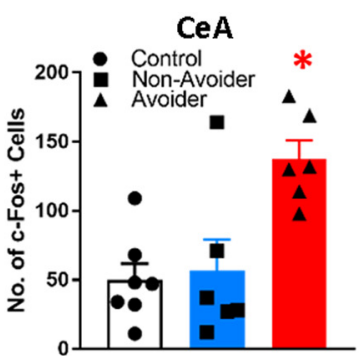

G

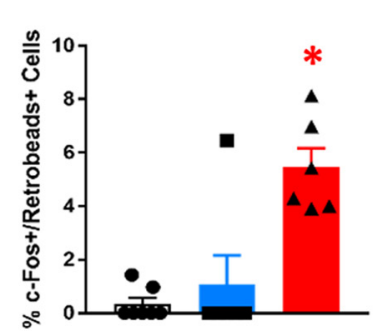

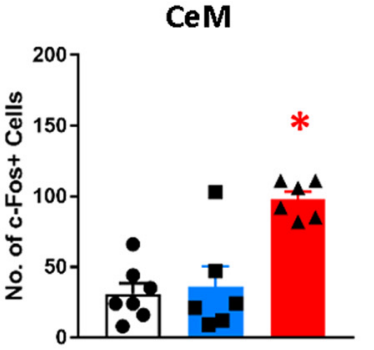

E

E
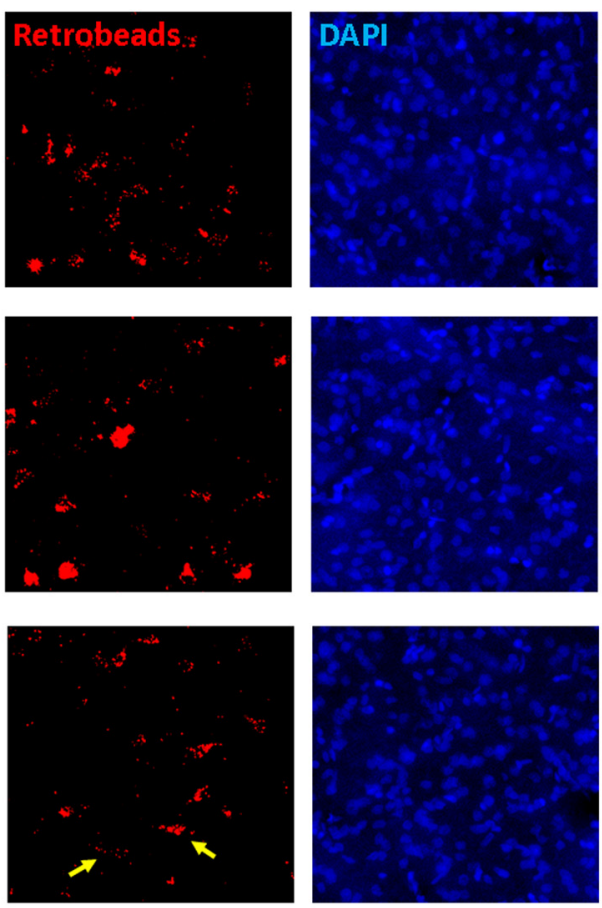

F
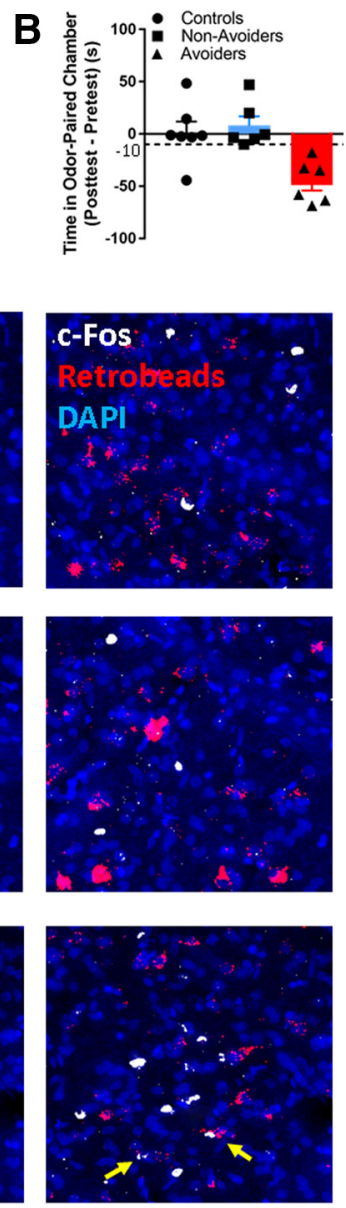

CeL

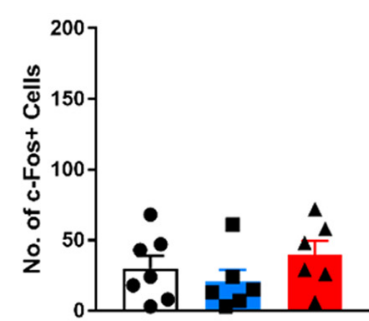

H
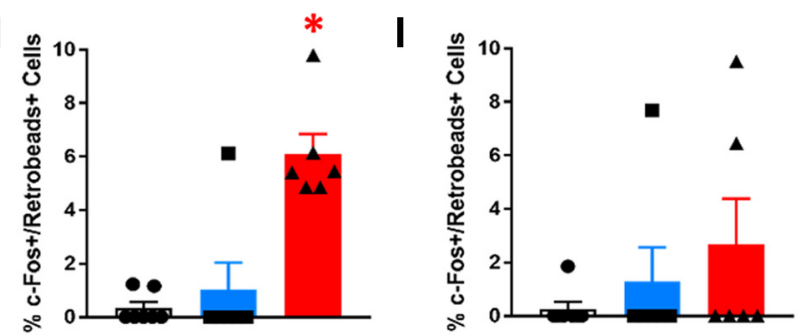

Figure 2. Avoiders have more c-Fos + CeA-LH cells. $\boldsymbol{A}$, Timeline schematic of experiment 2. B, Predator odor stress produces conditioned avoidance in a subset of rats. $\boldsymbol{C}$, Representative images of c-Fos + (white) and Retrobeads + (red) cells in the CeA of Controls, Non-Avoiders, and Avoiders (scale bar: $20 \mu \mathrm{m})$. Total number of c-Fos + cells in CeA (D), CeM (E), and CeL ( $\boldsymbol{F})$ of Avoiders (red), Non-Avoiders (blue), and Controls (black). Percent of c-Fos +/Retrobeads + cells over total Retrobeads + cells in CeA (G), CeM (H), and CeL ( $\boldsymbol{I})$ of Avoiders, Non-Avoiders, and Controls; $* p<0.05$ (see text for exact $p$ value), $n=6$ or 7 rats per group.

\section{Experiment 4}

The purpose of this experiment was to characterize the intrinsic properties and synaptic transmission of CeA-LH cells from Avoiders, NonAvoiders, and unstressed Controls, to test whether stress-induced alterations in these parameters may be associated with avoidance behavior. Studies have previously shown that alterations in synaptic transmission and/or intrinsic neuronal excitability properties in the amygdala measured ex vivo are associated with stress-related behavioral outcomes (Rosenkranz et al., 2010; Rau et al., 2015; Silveira Villarroel et al., 2018). Rats were given bilateral intra-LH green Retrobeads microinjections at least $6 \mathrm{~d}$ before the start of predator odor CPA. One day after CPA posttest, rats were re-exposed to predator odor (in a fashion identical to experiment 1; Fig. 2A) and killed $17 \mathrm{~h}$ later. We measured the following intrinsic neuronal excitability properties: resting membrane potential 
(RMP), input resistance, voltage SAG, and firing rate to input current response (Dembrow et al., 2010; Joshi et al., 2015; Avegno et al., 2018). We also recorded spontaneous IPSC (sIPSC) events while clamping the membrane voltage at $-50 \mathrm{mV}$ and spontaneous EPSCs (sEPSCs) while clamping the membrane voltage at $-70 \mathrm{mV}$. Recorded cells were generated from 17 rats.

\section{Experiment 5}

The purpose of this experiment was to test the contributions of specific HCN channels to voltage SAG in CeA-LH cells of Avoiders, NonAvoiders, and Controls. All procedures through killing were identical to experiment 3 . Here, we used the putative HCN1-selective blocker capsazepine (Gill et al., 2004) and compared relative SAG amplitude and kinetics before and after drug application to better understand the contribution of $\mathrm{HCN} 1$ versus non-HCN1 (HCN2-4) to previously observed stress effects on voltage SAG in LH-projecting CeA cells. Recorded cells were generated from 11 rats.

\section{Experimental design and statistical analyses}

Data were analyzed using omnibus factorial ANOVAs, with significant interactions followed-up with lower-order ANOVAs and Tukey's post hoc analyses. Within-subjects' factors include CeA subdivision (medial vs lateral) and test session, and between-subjects' factors include stress group (Avoider, Non-Avoider, Control) and treatment (vehicle, CNO), where appropriate. In DREADD experiments, animals that were given either active or control virus microinjections were analyzed separately (i. e., the control virus group was treated as a replication of the experiment; Smith et al., 2016). In all cases, the significance level was set at $p<0.05 ; t$ statistics from a two-sample $t$ test are also reported in pairwise comparisons. In experiment 4 , the relationship between SAG amplitude and timescale was quantified by using the Spearman rank-order correlation coefficient. This is a non-parametric correlation which is equivalent to the Pearson correlation coefficient of the rank values of the original data. Group means are shown with \pm SEM. All analyses were performed using the Statistical Package for Social Sciences software or MATLAB. Statistical details of experiments are reported in Results.

\section{Results}

\section{Experiment 1: CeA projections form functional connections with LH neurons}

The purpose of this experiment was to map CeA-LH projections using anatomic tracing and to test synaptic connections between $\mathrm{CeA}$ projections and $\mathrm{LH}$ cells using a combination of optogenetics and slice electrophysiology.

\section{CeA-LH anterograde tracing}

An anterograde tracer (AAV5-hSyn-mCherry) was microinjected into the CeA of rats and brain sections containing the $\mathrm{LH}$ were collected four weeks later. mCherry + terminals were present in the LH, particularly in the rostral region (bregma -1.8 to $-2.5)$. Within this region, mCherry+ terminals were mostly present in the dorsal and lateral areas of LH (Fig. 1A,B). mCherry + terminals were also present in neighboring areas such as medial amygdala (MeA) and zona incerta (ZI; Fig. 1A).

\section{CeA-LH slice electrophysiology}

AAV5-hSyn-hChR2-mCherry was microinjected into the CeA of rats and brain sections containing the $\mathrm{LH}$ were prepared for electrophysiological experiments four weeks later; 490-nm full-field LED light was used to visualize mCherry fluorescence in live brain slices. The spatial distribution of mCherry + axons was qualitatively similar to that observed in our fixed tissue experiments (Fig. 1A). Neurons ventral to the ZI and medial to the internal capsule were targeted for recordings. We found that $\mathrm{LH}$ neurons exhibited IPSC responses $(127 \pm 54 \mathrm{pA})$ when the slices were illuminated with blue light $(470 \mathrm{~nm})$ and that these responses were sensitive to PTX (100 $\mu \mathrm{M}$; Fig. $1 C)$. PTX significantly reduced the relative amplitude of optically evoked IPSCs in a subset of recorded LH neurons (0.08 $\pm 0.01, p<0.001$; Fig. $1 D)$. Also, to confirm that the CeA-LH pathway is monosynaptic, we recorded from several LH neurons with the sodium channel blocker TTX $(1 \mu \mathrm{M})$ and the potassium channel blocker 4AP (1 $\mathrm{mM})$. We used this approach because TTX blocks action potential generation of any potential di-synaptic intermediates, while 4AP compensates for the TTX-induced reduction in excitability at synaptic terminals. We found that direct synaptic responses persisted in the presence of TTX $+4 \mathrm{AP}$ (Fig. 1E); mean response amplitudes of optically evoked responses with circulating TTX + $4 \mathrm{AP}$ was $72.5 \pm 23.9 \mathrm{pA}(n=3)$.

\section{CeA- $L H$ retrograde tracing}

Retrobeads were microinjected into the LH (Fig. 1F), and rats were stressed and indexed for avoidance following the predator odor CPA procedure described above (Fig. 2A). Tissue sections from these rats were used for retrograde mapping of CeA-LH cells and for experiment 2 (see below). The number of Retrobeads + cells in both the lateral $(\mathrm{CeL})$ and medial (CeM) subdivisions of the CeA of Avoiders, Non-Avoiders, and Controls was quantified (Fig. $1 G$ ). An omnibus CeA subdivision $(\mathrm{CeM}, \mathrm{CeL}) \times$ stress group (Avoiders, Non-Avoiders, Controls) ANOVA revealed a main effect of CeA subdivision $\left(F_{(1,16)}=\right.$ 38.9, $p<0.001)$, indicating that there are more Retrobeads+ cells in CeM than in CeL (Fig. $1 H$ ). There were no differences in the number of Retrobeads + cells between stress groups.

\section{Crhr1 in situ hybridization in CeA-LH cells}

We next tested whether CeA-LH cells expressed Crhrl, a gene whose receptor product (CRF type-1 receptor) is highly expressed in CeA and mediate stress effects on behavior (Bruchas et al., 2009; Spierling and Zorrilla, 2017). Rats were given intra-LH microinjections of cholera toxin B conjugated with Alexa Fluor 555 (CTB555), killed one week later, and sections containing CeA were processed for RNAscope in situ hybridization of Crhrl. We found that a subset of CTB-555+ cells in CeA colocalized with Crhr1 (Fig. 1I).

\section{Experiment 2: CeA-LH cells are activated in avoiders after predator odor exposure}

The purpose of this experiment was to test the hypothesis that, after stress, Avoider rats have more activated (c-Fos+) CeA-LH cells than stressed Non-Avoiders and unstressed Controls. Rats were given intra-LH Retrobeads microinjections, exposed to predator odor stress and indexed for avoidance, and re-exposed to predator odor before their brains were collected for c-Fos immunohistochemistry (Fig. 2A). Stressed rats that showed a change in time spent in the predator odor-paired chamber of greater than $-10 \mathrm{~s}$ were classified as Avoiders (Fig. 2B). Avoider rats had more total c-Fos + cells (both Retrobeads + and - ) in the CeA than Non-Avoiders and Controls [one-way (stress group) ANOVA, significant effect of stress group $\left(F_{(2,16)}=8.8\right.$, $p=0.003$; Tukey's post hoc tests: $p=0.004$ (Avoiders vs Controls) and $p=0.009$ (Avoiders vs Non-Avoiders); Fig. 2C,D]. Analysis of c-Fos + cell counts in the medial (CeM) and lateral (CeL) subdivisions of the CeA (Fig. $1 F$ ) showed that Avoiders had more cFos + cells than Non-Avoiders and Controls in the CeM (Fig. $2 E$ ) but not CeL [Fig. 2F; significant CeA subdivision $\times$ stress group interaction $\left(F_{(2,16)}=8.7, p=0.003\right)$; significant effect of stress group in CeM only $\left(F_{(2,16)}=14.6, p<0.001\right)$; Tukey's post hoc tests: $p<0.001$ (Avoiders vs Controls) and $p=0.001$ (Avoiders vs Non-Avoiders)]. 
A

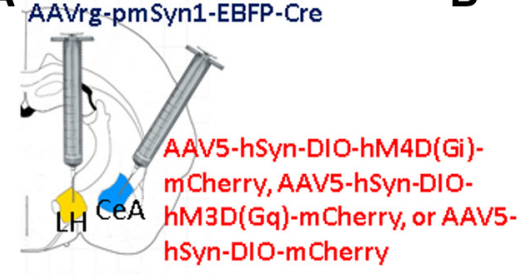

B

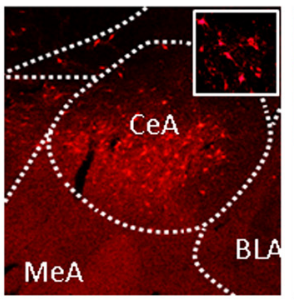

C

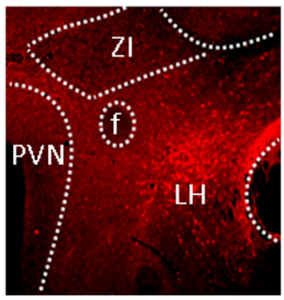

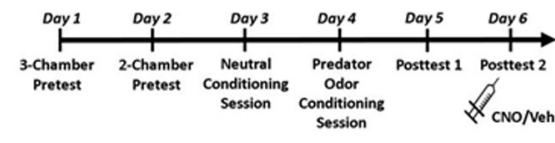

Control Virus

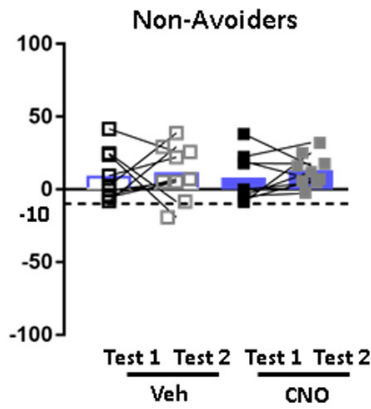

$\mathbf{E}$

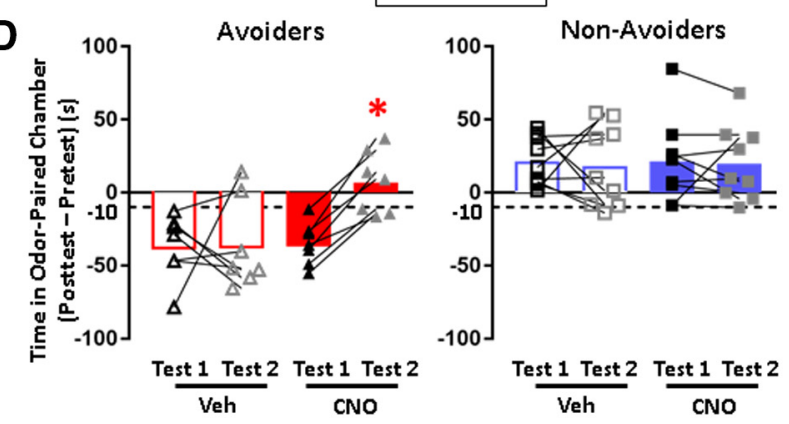

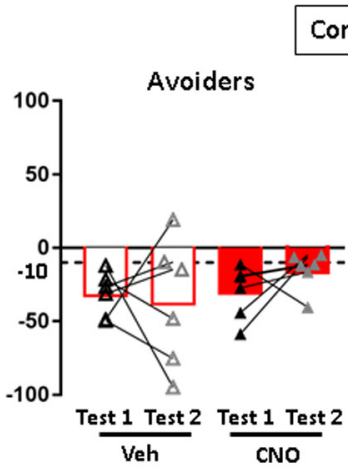

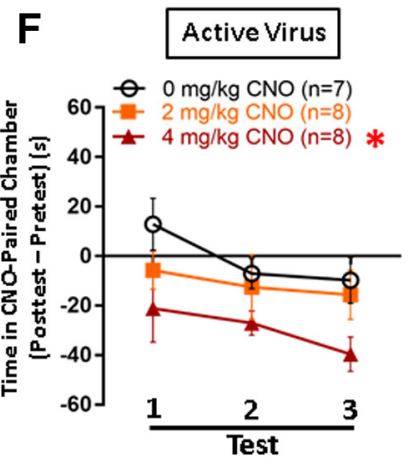

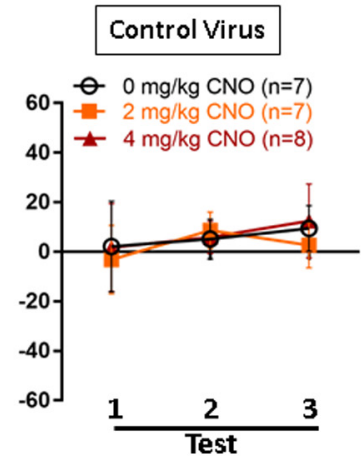

Figure 3. Conditioned avoidance of a predator odor-paired context is attenuated by CeA-LH cell inhibition and mimicked by CeA-LH cell activation. A, Schematic of intersectional viral expression strategy for targeting hM4D(Gi)-mCherry, hM3D(Gq)-mCherry, or mCherry control to CeA-LH cells. B, Image of mCherry expression in CeA cell bodies (left panel) and fibers in LH (right panel). BLA: basolateral amygdala, CeA: central amygdala, f: fornix, IC: internal capsule, LH: lateral hypothalamus, MeA: medial amygdala, Zl: zona incerta. C, Timeline schematic for testing the effect of CeA-LH circuit inhibition on avoidance behavior. D, Avoidance scores in Avoider and Non-Avoider rats that were given intra-CeA active Gi-DREADD or control virus and CNO or vehicle pretreatment during test 1 and test 2. E, Timeline schematic of CNO/vehicle place conditioning procedure. $\boldsymbol{F}$, Avoidance scores of rats that received intra-CeA active Gq-DREADD or control virus, split by CNO treatment group and across three posttest sessions; $* p<0.05$ (see text for exact $p$ values), $n=6-9$ rats per group.

Analysis of the percentage of c-Fos + Retrobeads + (i.e., cFos+ CeA-LH) cells showed that Avoiders had more c-Fos+ Retrobeads + cells in the CeA than Non-Avoiders and Controls [one-way ANOVA, significant effect of stress group $\left(F_{(2,16)}=8.7\right.$, $p=0.003$ ); Tukey's post hoc tests: $p=0.003$ (Avoiders vs Controls) and $p=0.013$ (Avoiders vs Non-Avoiders); Fig. 2C,G]. Analysis of c-Fos + cell counts in CeM and CeL subdivisions showed that Avoiders had more c-Fos + cells than Non-Avoiders and Controls in the CeM (Fig. $2 H$ ) but not CeL [Fig. 2I; subdivision $\times$ stress group interaction $\left(F_{(2,16)}=3.2, p=0.06\right)$; significant effect of stress group in CeM only $\left(F_{(2,16)}=12.4, p=0.001\right)$; Tukey's post hoc tests: $p=0.001$ (Avoiders vs Controls) and $p=0.003$ (Avoiders vs NonAvoiders)].

Experiment 3: in vivo modulation of CeA-LH cell activity affects avoidance behavior

CeA-LH circuit inhibition

The purpose of this experiment was to test the hypothesis that chemogenetic inhibition of CeA-LH cells attenuates conditioned avoidance of a predator odor stress-paired chamber in Avoider rats. The inhibitory Gi-DREADD receptor, $\mathrm{hM} 4 \mathrm{D}(\mathrm{Gi})$, was targeted to CeA-LH cells using an intersectional viral strategy (see Materials and Methods; Fig. 3A,B). Rats were stressed, indexed for avoidance (test 1), and retested for avoidance (test 2) following $\mathrm{CNO}$ or vehicle pretreatment (Fig. $3 \mathrm{C}$ ). In rats that received intra-CeA active virus (AAV5-hSyn-DIO-hM4D(Gi)-mCherry) microinjections, CNO treatment attenuated avoidance in Avoider rats but did not affect avoidance behavior in Non-Avoiders [test $\times$ treatment $\times$ stress group interaction $\left(F_{(1,28)}=3.3, p=0.068\right)$; significant test $\times$ treatment interaction in Avoiders only $\left(F_{(1,12)}=5.2\right.$, $p=0.041)$; significant effect of test in CNO-treated Avoiders only $\left(F_{(1,6)}=58.4, p<0.001\right)$; Fig. $\left.3 D\right]$. In rats that received intra-CeA control virus microinjections (AAV5-hSyn-mCherry), CNO treatment did not affect avoidance behavior in any rats (Fig. 3D).

\section{CeA-LH circuit stimulation}

The purpose of this experiment was to test the hypothesis that in vivo chemogenetic stimulation of CeA-LH cells is sufficient to support CPA. The stimulatory Gq-DREADD receptor, hM3D 
A

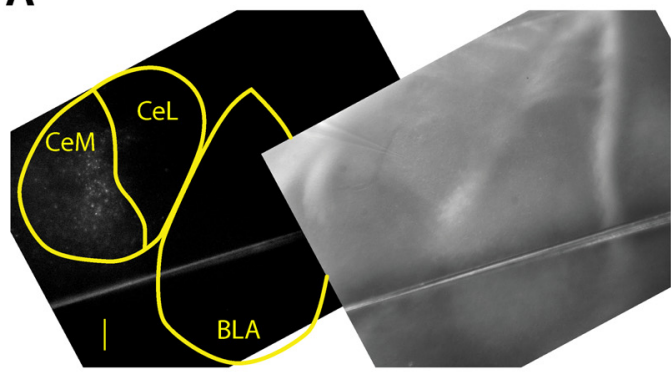

D

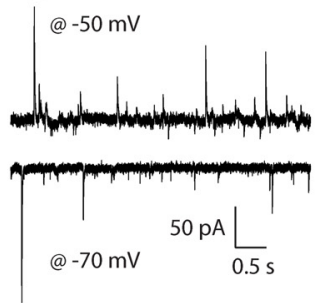

E

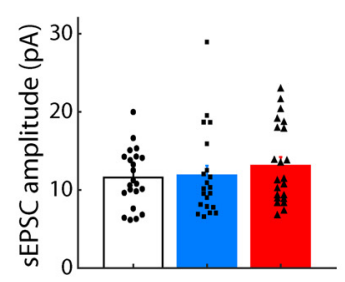

B

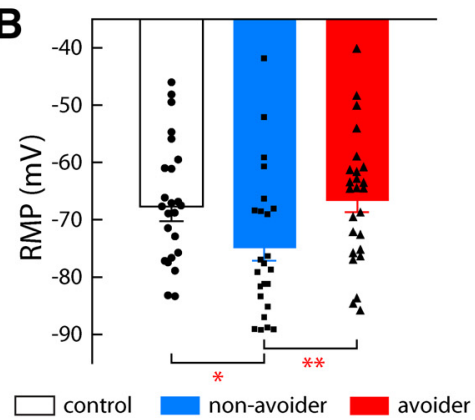

F

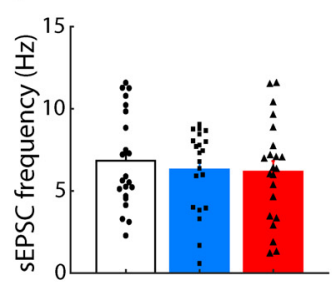

G

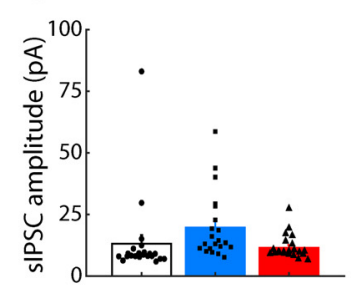

C

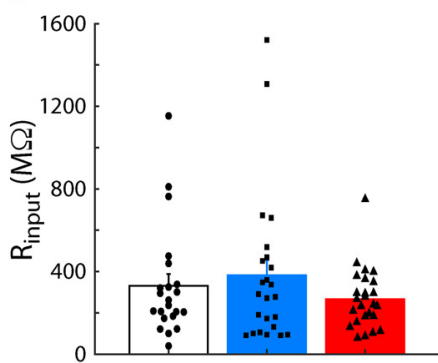

H
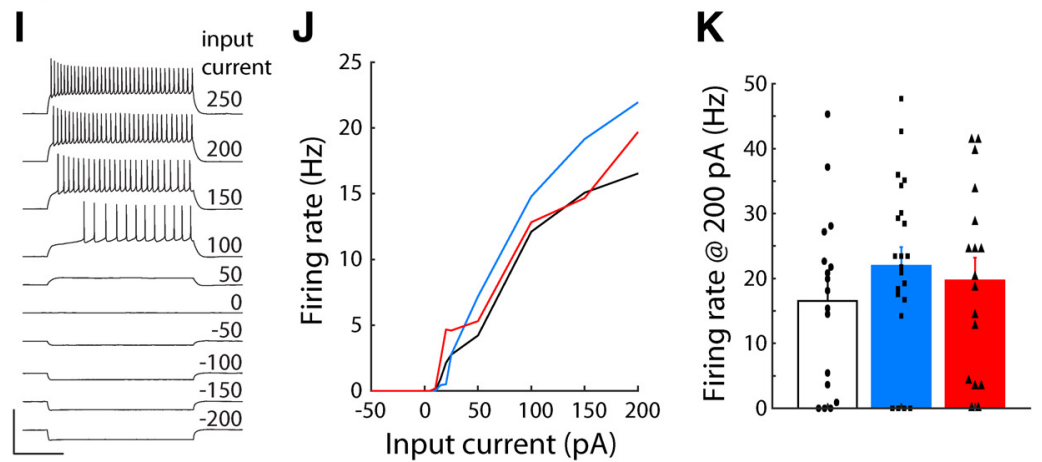

L

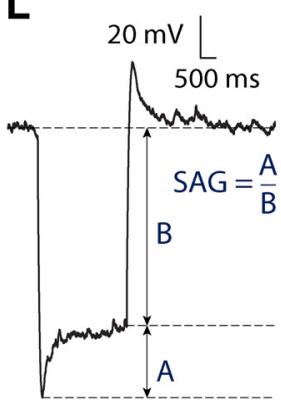

M

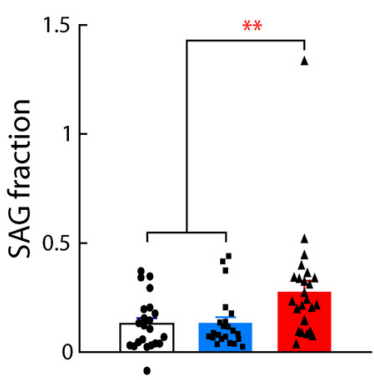

Figure 4. CeA-LH cells in Avoiders have altered intrinsic properties after stress. $A$, Representative image showing spatial distribution of fluorescent Retrobeads-labeled cells in CeA (scale bar: $200 \mu \mathrm{m})$. RMP $(\boldsymbol{B})$ and input resistance $(\boldsymbol{C})$ of CeA-LH cells in Avoiders, Non-Avoiders, and Controls. D, Example traces of postsynaptic currents from a CeA-LH cell recorded with membrane voltage clamped at -70 and $-50 \mathrm{mV}$. sEPSC event amplitude $(\boldsymbol{E})$ and frequency $(\boldsymbol{F})$ of CeA-LH cells in Avoiders, Non-Avoiders, and Controls. sIPSC event amplitude $(\boldsymbol{G})$ and frequency $(\boldsymbol{H})$ in CeA-LH cells of Avoiders, Non-Avoiders, and Controls. I, A set of membrane voltage responses in step current injections of varying amplitudes in an example CeA cell. Scale bars: $100 \mathrm{mV}$ and $500 \mathrm{~ms}$. J, Input-output current-firing rate function of CeA-LH cells in Avoiders, Non-Avoiders, and Controls constructed using spike counts from current step responses. $\boldsymbol{K}$, Firing rate in response to 200-pA step current injection. L, An example voltage trace (baseline $-70 \mathrm{mV}$ ) in response to a hyperpolarizing current. The SAG fraction is characterized as the ratio of: (1) the voltage difference between the minimum hyperpolarization and the new steady state voltage, and (2) the difference between new steady state and baseline resting voltage $(-70 \mathrm{mV})$. These quantities are denoted A and B, respectively, here. $\boldsymbol{M}$, The SAG voltage fraction of CeA $\rightarrow$ LH cells from Avoiders, Non-Avoiders, and Controls; $* p<0.05, * * p<0.01 ; n=74$ cells from 17 rats.

(Gq), was targeted to CeA-LH cells as described above (Fig. $3 A$, $B)$. Stress-naive rats were given CNO-paired or vehicle-paired place conditioning sessions on alternating days (see Materials and Methods; Fig. 3E). In rats that received intra-CeA microinjections of the active virus (AAV5-hSyn-DIO-hM3D(Gq)mCherry), $4 \mathrm{mg} / \mathrm{kg}$ CNO treatment produced CPA across three test sessions [significant main effect of CNO dose $\left(F_{(2,20)}=3.7\right.$, $p=0.042)$; Tukey's post hoc test: $p=0.041$ ( $4 \mathrm{vs} 0 \mathrm{mg} / \mathrm{kg} \mathrm{CNO}$ ); Fig. 3F, left panel]. Analysis of test 1 minus pretest time on the CNO-paired chamber showed that a single CNO conditioning trial produced a trend toward CPA $(p=0.1)$. Effects of CNO treatment did not significantly vary across test sessions (no significant test $\times$ treatment interaction). In rats that received intra$\mathrm{CeA}$ control virus microinjections, CNO treatment did not produce place conditioning (Fig. $3 F$, right panel).

\section{Experiment 4: CeA-LH cells in stressed rats have altered intrinsic properties}

The purpose of this experiment was to test the hypothesis that stress differentially alters intrinsic excitability of and spontaneous synaptic transmission onto LH-projecting cells in CeA in
Avoiders relative to Non-Avoiders and unstressed Controls. Brain slices containing CeA were illuminated with blue light to visualize cells labeled by a fluorescent retrograde tracer (green Retrobeads). We found that labeled cells were primarily localized to CeM (Fig. 4A). We exclusively targeted labeled cells for whole-cell recordings. Once whole-cell access was established in CeA-LH cells, we recorded spontaneous, resting membrane voltage traces in current clamp mode (with 0-pA injected current). We found that there was a main effect of stress group on RMP (one-way ANOVA, $F_{(2,67)}=3.92, p=0.025$ ). Cells from NonAvoiders had significantly lower RMP than either cells from Controls $\left(-74.9 \pm 2.2 \mathrm{vs}-67.7 \pm 2.5 \mathrm{mV} ; t_{(45)}=2.2 p<0.05\right)$ or Avoiders $\left(-66.7 \pm 2.0 \mathrm{mV} ; t_{(44)}=2.8 p=0.01\right.$; Fig. $\left.4 B\right)$. While recording in voltage clamp mode, we compared holding current at $-70 \mathrm{mV}$ and $-75 \mathrm{mV}$ to estimate input resistance (Fig. $4 \mathrm{C}$ ); we found no significant effect of stress group on input resistance between the three groups (one-way ANOVA, $F_{(2,71)}=1.1$, $p=0.34$ ). We then recorded 5-min traces of the holding current to detect and quantify spontaneous postsynaptic current events (Fig. 4D). We clamped the membrane voltage at $-70 \mathrm{mV}$ to isolate sEPSCs and then recorded successive traces while clamping 
A
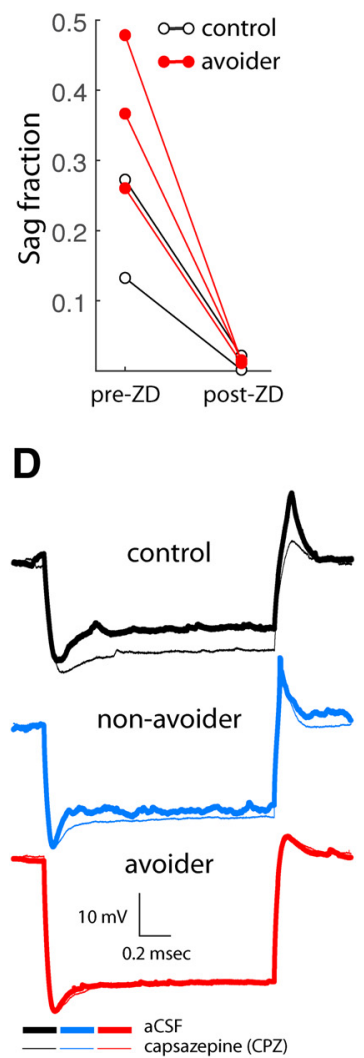

B

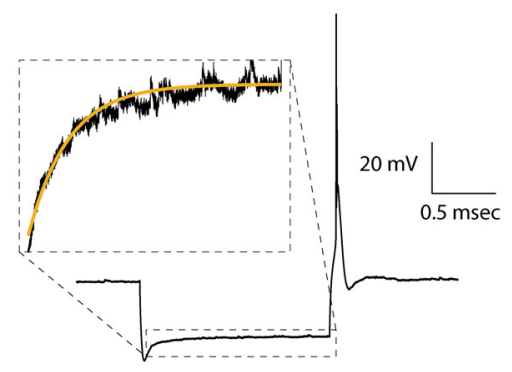

E

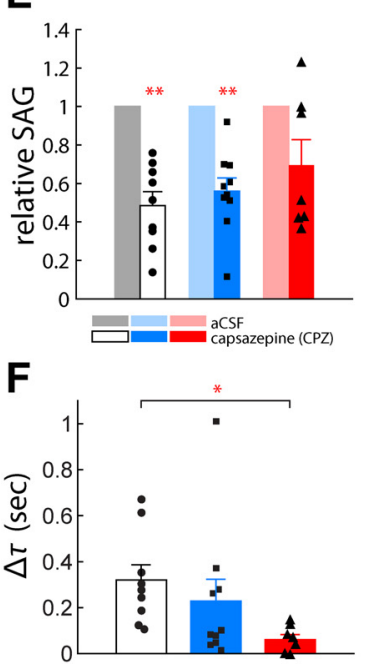

C

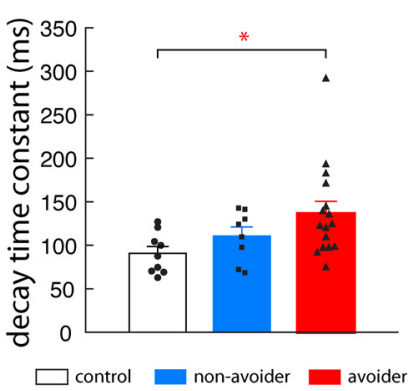

G

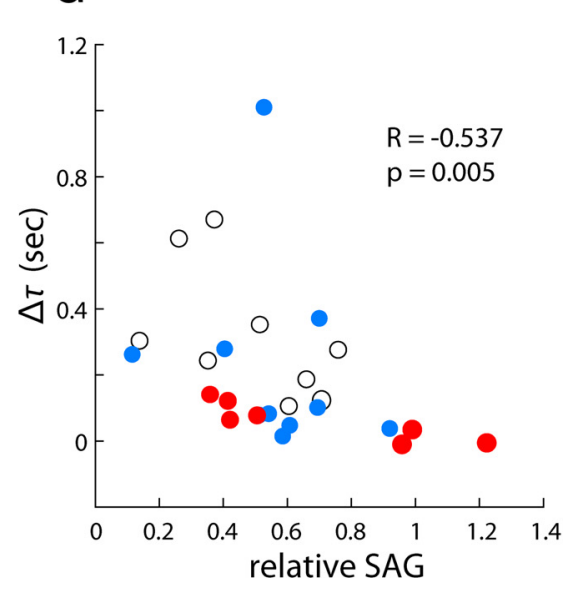

Figure 5. HCN subunit-specific function in CeA-LH cells after stress. A, SAG fraction magnitude pre-ZD7288 and post-ZD7288 (20 $\mu \mathrm{m})$ application. $\boldsymbol{B}$, Voltage SAG decay fitted with a single exponential decay function to estimate relative timescales of the voltage response from HCN currents. C, Decay timescale of the SAG in Avoiders, Non-Avoiders, and Controls. D, Example membrane voltage traces in response to hyperpolarizing step current injections before and after bath application of capsazepine $(20 \mu \mathrm{m})$ in Control, Non-Avoider, and Avoider rats. $\boldsymbol{E}$, Relative SAG magnitude in CeA-LH cells of Avoiders, Non-Avoiders, and Controls following capsazepine application. $\boldsymbol{F}$, The change in decay time constant of the voltage SAG after capsazepine bath application. $\mathbf{G}$, Correlation between relative SAG amplitude and change in timescale (from $\boldsymbol{E}, \boldsymbol{F}$ ) when data from Avoiders, Non-Avoiders, and Controls are pooled; $* p<0.05, * * p<0.01 ; n=26$ cells from 15 rats.

at $-50 \mathrm{mV}$ to observe sIPSCs. The polarity of sIPSCs is opposite that of sEPSCs (outwards vs inward current) so to detect inhibitory events the event detection threshold was set above the baseline holding current; additionally, individual waveforms were manually confirmed after analysis to confirm recording of sIPSCs. One-way ANOVAs of stress group indicated there were no significant differences in sEPSC or sIPSC amplitude $\left(F_{(2,54)}=\right.$ $1.3, p=0.28)$ or frequency $\left(F_{(2,54)}=0.9, p=0.41\right.$; Fig. $\left.4 E-H\right)$. Next, voltage traces (in current clamp recording mode) were recorded while injecting step currents of varying amplitudes into the cell (Fig. 4I); action potentials during the step current duration were counted for each response to construct input-output firing rate response curves (Fig. $4 J$ ). We compared the firing rates at 200-pA step current injection and found that there was no effect of stress group (one-way ANOVA $F_{(2,56)}=1.1, p=0.33$; Fig. $4 K)$. Negative current steps hyperpolarized cell membrane voltage; in some cells the membrane returned to more positive intermediate steady state voltages (Fig. $4 L$ ). This characteristic voltage excursion is known as the voltage SAG (Dembrow et al., 2010; Joshi et al., 2015) and is reflective of subthreshold current mediated HCN channels, also known as $I_{h}$. Voltage SAG fraction was recorded in response to hyperpolarizing step current injection. We found that there was a main effect of stress group on voltage SAG (one-way ANOVA, $F_{(2,66)}=5.1, p=0.009$ ). Cells from Avoiders exhibited significantly greater SAG than cells from unstressed Controls $\left(0.28 \pm 0.05\right.$ vs $0.13 \pm 0.03, t_{(45)}=2.5$, $p=0.0023$ and Non-Avoiders $\left(0.13 \pm 0.03, t_{(45)}=2.4, p=0.0025\right.$; Fig. 4M).

\section{Experiment 5: HCN subunit-specific function in CeA-LH cells}

The purpose of this experiment was to test the contribution of $\mathrm{HCN}$ channels in general and also specific HCN channel subunits (i.e., HCN1) to stress effects on hyperpolarization activated voltage rebound (or voltage SAG) in CeA-LH cells observed in experiment 3. Currents from HCN channels, denoted $I_{h}$, can influence single cell and network rhythmic activity, postinhibitory rebound excitation and synaptic plasticity (Brown and Difrancesco, 1980; Bobker and Williams, 1989; Dickson et al., 2000; Biel et al., 2009; Wahl-Schott and Biel, 2009; Ferrante et al., 2017). To confirm that the observed voltage SAG depends on HCN channel function, we applied the HCN blocker ZD7288 to the aCSF bath in select cells exhibiting reliable SAG $(>0.1)$ and confirmed that the SAG fraction was reduced to near zero values in Control and Avoider rats (Fig. 5A). The HCN channel family is comprised of four isoforms, subunits HCN1-HCN4, each with distinct activation timescales. Specifically, HCN1 exhibits the fastest kinetics while HCN4 exhibits the slowest (Altomare et al., 2003). To explore the potential subunits contributing to our observed HCN channel-mediated SAG, we fit an exponential to 
the decaying phase of the SAG approach to new steady state (Fig. $5 B)$. The decay time constant of the best fit exponential for voltage traces with a SAG fraction above 0.1 were compared between Controls, Non-Avoiders, and Avoiders (Fig. 5C). One-way ANOVA revealed a main effect of stress group on decay timescale of the HCN current $\left(F_{(2,66)}=3.6, p=0.041\right)$. Pairwise comparisons revealed a significantly slower decay timescale of $\mathrm{HCN}$ currents in cells from Avoiders $(136.5 \pm 13.3 \mathrm{~ms})$ relative to Controls $\left(90.8 \pm 7.8 \mathrm{~ms} ; t_{(23)}=2.4, p=0.036\right)$. To further explore the potential subunit dependence of HCN-mediated currents, we compared the stereotypical voltage SAG, indicative of HCN activation, in our recorded traces before and after bath application of the putative HCN1-selective antagonist capsazepine (Fig. 5D; Gill et al., 2004). While recording in current clamp mode, we hyperpolarized cells ( -100 - to $-200-\mathrm{pA}$ current steps) and quantified the voltage SAG. We then bath applied capsazepine $(30 \mu \mathrm{M})$ and calculated the relative change in SAG amplitude. Capsazepine significantly reduced the magnitude of SAG (relative to baseline) in CeA-LH cells from unstressed Controls $\left(0.49 \pm 0.07\right.$; paired t test, $t_{(8)}=7.2 p<0.001$ and Non-Avoiders $\left(0.56 \pm 0.07\right.$; paired t test, $\left.t_{(9)}=6.6, p<0.001\right)$, but not Avoider rats $\left(0.70 \pm 0.13\right.$; paired $t$ test, $t_{(6)}=2.3, p=0.06$; Fig. $\left.5 E\right)$. We calculated the time constants of the voltage SAG decay to steady state and calculated the difference between precapsazepine and postcapsazepine values. One-way ANOVA did not reveal a significant main effect of capsazepine on change in SAG timescale $(p=0.16)$, but the change decay time constant of the voltage SAG before and after capsazepine bath application was significantly larger in CeA-LH cells from unstressed Control rats (309 \pm $70 \mathrm{~ms})$ relative to cells from Avoider rats $\left(61 \pm 22, t_{(14)}=3.0\right.$, $p=0.005$; Fig. $5 F$ ). To examine coordinated changes in capsazepine-induced SAG amplitude reduction and increase in SAG decay timescales, we calculated the correlation (Spearman correlation coefficient) between the relative SAG and decay time constant for the pooled data set. These quantities were significantly negatively correlated $(\mathrm{R}=-0.537, p=0.005)$ meaning that after bath application of capsazepine, large reductions in SAG amplitude were generally associated with large increases in SAG timescale (i.e., slower approach of voltage to steady state) particularly in Controls and Non-Avoiders (Fig. 5G). This is consistent with a scenario where larger reductions in SAG amplitude is because of reduction in current from $\mathrm{HCN}$ subunits with the fastest timescales, i.e., $\mathrm{HCN} 1$ subunits.

\section{Discussion}

The purpose of this study was to test the hypotheses that predator odor stress (i.e., bobcat urine) activates CeA-LH projections in Avoiders, that CeA-LH circuit inhibition attenuates predator odor conditioned avoidance in Avoiders, that CeA-LH circuit activation is sufficient to support the development of CPA in unstressed animals, and to characterize the topographical and physiological properties of these projections at baseline and after predator odor exposure. We first confirmed that CeA cells form functional GABAergic synaptic contacts onto LH cells using a combination of anterograde and retrograde tracing, optogenetics and slice electrophysiology. Stress activated a higher number of $\mathrm{CeA}-\mathrm{LH}$ projection cells in Avoider rats relative to stressed NonAvoiders and unstressed Controls, as measured by c-Fos induction. Chemogenetic inhibition of CeA-LH projections attenuated predator odor conditioned avoidance in Avoider rats and chemogenetic stimulation of this circuit in unstressed rats supported the development of CPA. Slice electrophysiology studies revealed that CeA-LH projections have more hyperpolarized RMPs in Non-Avoiders and show greater voltage SAG in Avoiders. In addition, our data suggest that voltage SAG in Avoiders have a smaller HCN1 subunit contribution compared with voltage SAG in stressed Non-Avoiders and unstressed Controls. To our knowledge, this is the first demonstration of a functional role for $\mathrm{CeA}-\mathrm{LH}$ projections in behavior.

\section{Function of CeA-LH projections}

The CeA mediates the behavioral and physiological effects of stress and specific CeA output projections have defined roles in stress-related alterations in physiology and behavior. For example, CeA projections to the paraventricular nucleus of the hypothalamus (PVN) stimulate the hypothalamic-pituitary-adrenal axis (Feldman and Weidenfeld, 1998) and projections to the locus coeruleus drive noradrenergic activity (Bouret et al., 2003) and anxiety-like behavior (McCall et al., 2015). To our knowledge, there are no published studies on the role of CeA projections to LH in behavior. This study shows that predator odor stress preferentially activates CeA-LH projection cells in Avoiders, that chemogenetic inhibition of CeA-LH cells attenuates predator odor-induced CPA, and that chemogenetic stimulation of CeA-LH cells in otherwise experimentally naive rats supports the development of CPA. Collectively, these results suggest that CeA-LH projections are important for mediating avoidance of aversive stimuli. One caveat to note is that the intersectional virus strategy used here to express DREADD receptors $\mathrm{hM} 4 \mathrm{D}(\mathrm{Gi})$ and hM3D $(\mathrm{Gq})$ (intra-LH microinjections of a retrocre $\mathrm{AAV}$ and intra-CeA microinjections of a cre-dependent $\mathrm{hM} 4 \mathrm{D}(\mathrm{Gi})$ or hM3D(Gq)) and systemic delivery of CNO may produce activation of $\mathrm{CeA}-\mathrm{LH}$ projections that have collateral projections to other brain areas. However, $\mathrm{hM} 3 \mathrm{D}(\mathrm{Gq})$ expression was not detected in several brain areas that surround the $\mathrm{LH}$ and that are known to receive CeA inputs [e.g., ZI (Zhou et al., 2018) and PVN (Gray et al., 1989)].

Previous studies showed that LH lesions disrupt autonomic (arterial pressure) but not behavioral responses (freezing) to fear conditioning (Iwata et al., 1986; LeDoux et al., 1988). Findings reported here suggest that the LH may mediate specific types of aversion-related behavioral responses. This finding complements recent work in mice showing that $\mathrm{LH} \mathrm{Hcrt+} \mathrm{cells,} \mathrm{which} \mathrm{receive}$ inputs from several brain areas including $\mathrm{CeA}$, become activated during predator odor (fox urine) exposure, as indicated by fiber photometry, and that optical stimulation of LH Hcrt+ cells produces real-time place avoidance (Giardino et al., 2018). Future work should elucidate the molecular phenotypes of LH cells receiving CeA innervation, of CeA cells projecting to $\mathrm{LH}$, and their roles in stress-related behaviors. Here, using RNAscope, we showed that a subset of CeA-LH cells are CRFR1+ (Crhr1expressing). We are currently testing the role of CRFR1+ CeA$\mathrm{LH}$ neurons in mediating effects of predator odor stress on behavior.

\section{Topography of CeA-LH projections}

The topography of CeA-LH projections provides information on the potential phenotypes of CeA and $\mathrm{LH}$ cells participating in this circuitry. Here, we report that a majority of CeA-LH projections originate from the $\mathrm{CeM}$, as indicated by retrograde tracing using Retrobeads, consistent with previous findings in LongEvans (Reppucci and Petrovich, 2016) and Sprague Dawley rats (Barbier et al., 2018). The CeL contains a high density of CRFexpressing cells that release CRF both locally and distally (Pomrenze et al., 2015), whereas the CeM contains a high density 
of CRFR1-expressing cells that can be activated by CRF (Radulovic et al., 1998). This anatomic distribution, along with prior findings that predator odor stress increases CRF peptide content in CeA of Avoiders and CRFR1 antagonism in CeA reduces avoidance, escalated alcohol drinking (Weera et al., 2020), and hyperalgesia in Avoiders (Itoga et al., 2016), makes it reasonable to hypothesize that CRFR1 may be enriched on CeA-LH cells and may gate the activity of this circuit, especially because we show here that a subset of CeA-LH cells are CRFR1+.

Using an mCherry-expressing AAV5 anterograde tracer, we report that CeA cells mostly project to the rostrodorsal $\mathrm{LH}$, in agreement with a study by Reppucci and Petrovich (2016) in rats. In addition, Barbier et al. (2018) showed that cells from caudal CeM project to this region of $\mathrm{LH}$ in rats. The rostrodorsal $\mathrm{LH}$ is a heterogeneous area but contains a relatively high density of Hcrt + cells in rats (Barbier et al., 2018), and LH Hcrt + cells have been implicated in avoidance behavior in mice (Giardino et al., 2018). Indeed, previous work in mice showed that CeA projections innervate LH Hcrt+ cells (Nakamura et al., 2009), supporting the idea that CeA cells may drive avoidance via modulation of $\mathrm{LH}$ Hcrt + cell activity. That said, other studies have demonstrated that Hcrt- cells in the dorsal LH can also drive avoidance behavior (e.g., VGlut2+ cells; Lazaridis et al., 2019).

\section{Physiologic correlates of $\mathrm{CeA}-\mathrm{LH}$ projection activation}

After finding that stress preferentially activates CeA-LH cells in Avoiders (as measured by c-Fos induction) and that chemogenetic modulation of CeA-LH cell activity in vivo affects avoidance behavior, we examined stress effects on the physiological properties of CeA-LH cells in Avoiders, Non-Avoiders, and unstressed Controls. Previous studies showed that stress-induced alterations in synaptic transmission and/or intrinsic excitability properties (e.g., RMP, $I_{h}$, etc.) may contribute to stress-related outcomes (Rosenkranz et al., 2010; Rau et al., 2015; Silveira Villarroel et al., 2018). Spontaneous synaptic transmission (i.e., sEPSC and sIPSC) did not differ between groups, thus we conclude that stress-driven modifications in the synaptic circuitry onto CeA-LH cells do not underlie poststress avoidance. We next examined cell excitability properties related to action potential generation, and we found that input resistance and firing rate gain did not differ between groups. We observed that the RMP was significantly lower in Non-Avoiders than in Avoiders or Controls, which suggests that lower RMP in Non-Avoiders may buffer CeA-LH cells against stimuli (e.g., stress) that produce cellular hyperactivity (and this may be absent or deficient in Avoiders). Finally, we observed that the voltage SAG amplitude (reflecting HCN-mediated currents) was significantly larger in Avoider cells than in Non-Avoider or Control cells. HCN currents influence several aspects of neural and network activity: they can depolarize membrane potentials (inward current), generate subthreshold oscillations, and postinhibitory rebound mediated by $I_{h}$ may help synchronize network rhythms (Brown and Difrancesco, 1980; Bobker and Williams, 1989; Dickson et al., 2000; Biel et al., 2009; Wahl-Schott and Biel, 2009; Ferrante et al., 2017). We did not test network activity in CeA-LH cells in vivo, but the functional effects of larger $I_{h}$ in Avoiders may contribute to hyperactivity of CeA-LH cells and/or increased functional coupling of CeA and $\mathrm{LH}$ cells by synchronized rhythmic activity. Past work identified an association between ex vivo $I_{h}$ function and in vivo stress effects: more specifically, virally mediated knockdown of $I_{h}$ (specifically that mediated by HCN1) in the basolateral amygdala underlies resilience to stress in rats, measured by social interaction time after $30 \mathrm{~min}$ of restraint
(Silveira Villarroel et al., 2018). Similarly, our findings suggest that larger $I_{h}$ in CeA-LH cells is positively associated with higher stress reactivity (i.e., higher avoidance of stress-paired stimuli). To understand whether HCN channel subunit-specific changes were associated with different behavioral phenotypes, we used HCN channel subunit-selective pharmacology in our brain slice recordings. Our results suggest that $I_{h}$ in CeA-LH cells from Non-Avoiders and unstressed Controls is largely mediated by HCN1 subunits, whereas $I_{h}$ in CeA-LH cells from Avoiders is mediated in larger part by non-HCN1 subunits (e.g., HCN2-4). Together, these findings suggest that several physiological factors (i.e., RMP, $I_{h}$ and non-HCN1-subunits) are associated with poststress avoidance and may modulate stress reactivity.

Collectively, these data suggest that CeA cells make functional GABAergic synaptic contacts on $\mathrm{LH}$ cells, that stress activates $\mathrm{LH}$-projecting cells in the CeA of Avoiders, that these cells largely originate in the CeM and project to the rostrodorsal $\mathrm{LH}$, that activation of these cells support the development of conditioned avoidance behavior in stress-naive rats and inhibition of these cells reduces avoidance of a stress-paired context in Avoider rats, and that stress alters intrinsic properties (e.g., RMP, SAG) of LH-projecting cells in Avoider and Non-Avoider rats. Future studies will investigate the molecular signature of cells in this circuit and determine whether specific HCN channel subunit signaling in this circuit is important for mediating stress effects on behavior.

\section{References}

Albrechet-Souza L, Gilpin NW (2019) The predator odor avoidance model of post-traumatic stress disorder in rats. Behav Pharmacol 30:105-114.

Altomare C, Terragni B, Brioschi C, Milanesi R, Pagliuca C, Viscomi C, Moroni A, Baruscotti M, DiFrancesco D (2003) Heteromeric HCN1HCN4 channels: a comparison with native pacemaker channels from the rabbit sinoatrial node. J Physiol 549:347-359.

Avegno EM, Lobell TD, Itoga CA, Baynes BB, Whitaker AM, Weera MM, Edwards S, Middleton JW, Gilpin NW (2018) Central amygdala circuits mediate hyperalgesia in alcohol-dependent rats. J Neurosci 8:7761-7773.

Barbier M, Fellmann D, Risold PY (2018) Morphofunctional organization of the connections from the medial and intermediate parts of the central nucleus of the amygdala into distinct divisions of the lateral hypothalamic area in the rat. Front Neurol 9:688.

Biel M, Wahl-Schott C, Michalakis S, Zong X (2009) Hyperpolarization-activated cation channels: from genes to function. Physiol Rev 89:847-885.

Bobker DH, Williams JT (1989) Serotonin augments the cationic current Ih in central neurons. Neuron 2:1535-1540.

Bouret S, Duvel A, Onat S, Sara SJ (2003) Phasic activation of locus ceruleus neurons by the central nucleus of the amygdala. J Neurosci 23:3491-3497.

Breslau N (2009) The epidemiology of trauma, PTSD, and other posttrauma disorders. Trauma Violence Abuse 10:198-210.

Brown H, Difrancesco D (1980) Voltage-clamp investigations of membrane currents underlying pace-maker activity in rabbit sino-atrial node. J Physiol 308:331-351.

Bruchas MR, Land BB, Lemos JC, Chavkin C (2009) CRF1-R activation of the dynorphin/kappa opioid system in the mouse basolateral amygdala mediates anxiety-like behavior. PLoS One 4:e8528.

Bryant RA, Harvey AG (1995) Avoidant coping style and post-traumatic stress following motor vehicle accidents. Behav Res Ther 33:631-635.

Bryant RA, Marosszeky JE, Crooks J, Baguley I, Gurka J (2000) Coping style and post-traumatic stress disorder following severe traumatic brain injury. Brain Inj 14:175-180.

Dembrow NC, Chitwood RA, Johnston D (2010) Projection-specific neuromodulation of medial prefrontal cortex neurons. J Neurosci 30:1692216937.

Dickson CT, Magistretti J, Shalinsky MH, Fransén E, Hasselmo ME, Alonso A (2000) Properties and role of $\mathrm{I}(\mathrm{h})$ in the pacing of subthreshold oscillations in entorhinal cortex layer II neurons. J Neurophysiol 83:2562-2579.

Edwards S, Baynes BB, Carmichael CY, Zamora-Martinez ER, Barrus M, Koob GF, Gilpin NW (2013) Traumatic stress reactivity promotes 
excessive alcohol drinking and alters the balance of prefrontal cortexamygdala activity. Transl Psychiatry 3:e296.

Feldman S, Weidenfeld J (1998) The excitatory effects of the amygdala on hypothalamo-pituitary-adrenocortical responses are mediated by hypothalamic norepinephrine, serotonin, and CRF-41. Brain Res Bull 45:389-393.

Ferrante M, Shay CF, Tsuno Y, William Chapman G, Hasselmo ME (2017) Post-inhibitory rebound spikes in rat medial entorhinal layer II/III principal cells: in vivo, in vitro, and computational modeling characterization. Cereb Cortex 27:2111-2125.

Giardino WJ, Eban-Rothschild A, Christoffel DJ, Li SB, Malenka RC, de Lecea L (2018) Parallel circuits from the bed nuclei of stria terminalis to the lateral hypothalamus drive opposing emotional states. Nat Neurosci 21:1084-1095.

Gill CH, Randall A, Bates SA, Hill K, Owen D, Larkman PM, Cairns W, Yusaf SP, Murdock PR, Strijbos PJLM, Powell AJ, Benham CD, Davies $\mathrm{CH}$ (2004) Characterization of the human HCN1 channel and its inhibition by capsazepine. Br J Pharmacol 143:411-421.

Gray TS, Carney ME, Magnuson DJ (1989) Direct projections from the central amygdaloid nucleus to the hypothalamic paraventricular nucleus: possible role in stress-induced adrenocorticotropin release. Neuroendocrinology 50:433-446.

Itoga CA, Roltsch Hellard EA, Whitaker AM, Lu Y-L, Schreiber AL, Baynes BB, Baiamonte BA, Richardson HN, Gilpin NW (2016) Traumatic stress promotes hyperalgesia via corticotropin-releasing factor-1 receptor (CRFR1) signaling in central amygdala. Neuropsychopharmacology 41 : 2463-2472.

Iwata J, LeDoux JE, Reis DJ (1986) Destruction of intrinsic neurons in the lateral hypothalamus disrupts the classical conditioning of autonomic but not behavioral emotional responses in the rat. Brain Res 368:161-166.

Jennings JH, Rizzi G, Stamatakis AM, Ung RL, Stuber GD (2013) The inhibitory circuit architecture of the lateral hypothalamus orchestrates feeding. Science 341:1517-1521.

Jennings JH, Ung RL, Resendez SL, Stamatakis AM, Taylor JG, Huang J, Veleta K, Kantak PA, Aita M, Shilling-Scrivo K, Ramakrishnan C, Deisseroth K, Otte S, Stuber GD (2015) Visualizing hypothalamic network dynamics for appetitive and consummatory behaviors. Cell 160:516-527.

Joshi A, Middleton JW, Anderson CT, Borges K, Suter BA, Shepherd GMG, Tzounopoulos T (2015) Cell-specific activity-dependent fractionation of layer $2 / 3 \rightarrow 5 \mathrm{~B}$ excitatory signaling in mouse auditory cortex. J Neurosci 35:3112-3123.

Kotler M, Finkelstein G, Molcho A, Botsis AJ, Plutchik R, Brown S-L, van Praag HM (1993) Correlates of suicide and violence risk in an inpatient population: coping styles and social support. Psychiatry Res 47:281-290.

Krettek JE, Price JL (1978) Amygdaloid projections to subcortical structures within the basal forebrain and brainstem in the rat and cat. J Comp Neurol 178:225-254.

Lazaridis I, Tzortzi O, Weglage M, Märtin A, Xuan Y, Parent M, Johansson Y, Fuzik J, Fürth D, Fenno LE, Ramakrishnan C, Silberberg G, Deisseroth K, Carlén M, Meletis K (2019) A hypothalamus-habenula circuit controls aversion. Mol Psychiatry 24:1351-1368.

LeDoux JE, Iwata J, Cicchetti P, Reis DJ (1988) Different projections of the central amygdaloid nucleus mediate autonomic and behavioral correlates of conditioned fear. J Neurosci 8:2517-2529.

Linehan MM, Chiles JA, Egan KJ, Devine RH, Laffaw JA (1986) Presenting problems of parasuicide versus suicide ideators and nonsuicidal psychiatric patients. J Consult Clin Psychol 54:880-881.

Mayeux J, Katz P, Edwards S, Middleton JW, Molina PE (2017) Inhibition of endocannabinoid degradation improves outcomes from mild traumatic brain injury: A mechanistic role for synaptic hyperexcitability. J Neurotrauma 34:436-443.

McCall JG, Al-Hasani R, Siuda ER, Hong DY, Norris AJ, Ford CP, Bruchas MR (2015) CRH engagement of the locus coeruleus noradrenergic system mediates stress-induced anxiety. Neuron 87:605-620.

Mezzich AC, Tarter RE, Kirisci L, Hsieh YC, Grimm M (1995) Coping capacity in female adolescent substance abusers. Addict Behav 20:181-187.

Moos RH, Schaefer J (1993) Coping resources and processes: current concepts and measures. In: Handbook of stress: theoretical and clinical aspects, Ed 2 (Goldberger L, Breznitz S, eds), pp 234-257. New York: MacMillan.
Nakamura S, Tsumori T, Yokota S, Oka T, Yasui Y (2009) Amygdaloid axons innervate melanin-concentrating hormone- and orexin-containing neurons in the mouse lateral hypothalamus. Brain Res 1278:66-74.

Perkonigg A, Pfister H, Stein MB, Höfler M, Lieb R, Maercker A, Wittchen HU (2005) Longitudinal course of posttraumatic stress disorder and posttraumatic stress disorder symptoms in a community sample of adolescents and young adults. Am J Psychiatry 162:1320-1327.

Pomrenze MB, Millan EZ, Hopf FW, Keiflin R, Maiya R, Blasio A, Dadgar J, Kharazia V, De Guglielmo G, Crawford E, Janak PH, George O, Rice KC, Messing RO (2015) A transgenic rat for investigating the anatomy and function of corticotrophin releasing factor circuits. Front Neurosci 9:487.

Radulovic J, Sydow S, Spiess J (1998) Characterization of native corticotropin-releasing factor receptor type 1 (CRFR1) in the rat and mouse central nervous system. J Neurosci Res 54:507-521.

Rau AR, Chappell AM, Butler TR, Ariwodola OJ, Weiner JL (2015) Increased basolateral amygdala pyramidal cell excitability may contribute to the anxiogenic phenotype induced by chronic early-life stress. J Neurosci 35:9730-9740.

Reppucci CJ, Petrovich GD (2016) Organization of connections between the amygdala, medial prefrontal cortex, and lateral hypothalamus: a single and double retrograde tracing study in rats. Brain Struct Funct 221:29372962.

Rosenkranz JA, Venheim ER, Padival M (2010) Chronic stress causes amygdala hyperexcitability in rodents. Biol Psychiatry 67:1128-1136.

Shin KM, Chang HY, Cho S-M, Kim NH, Kim KA, Chung YK (2015) Avoidance symptoms and delayed verbal memory are associated with post-traumatic stress symptoms in female victims of sexual violence. J Affect Disord 184:145-148.

Silveira Villarroel H, Bompolaki M, Mackay JP, Miranda Tapia AP, Michaelson SD, Leitermann RJ, Marr RA, Urban JH, Colmers WF (2018) NPY induces stress resilience via downregulation of $I_{\mathrm{h}}$ in principal neurons of rat basolateral amygdala. J Neurosci 38:4505-4520.

Smith KS, Bucci DJ, Luikart BW, Mahler SV (2016) DREADDs: use and application in behavioral neuroscience. Behav Neurosci 130:137-155.

Spierling SR, Zorrilla EP (2017) Don't stress about CRF: assessing the translational failures of CRF1 antagonists. Psychopharmacology (Berl) 234:1467-1481.

Sripada RK, Rauch SAM, Tuerk PW, Smith E, Defever AM, Mayer RA, Messina M, Venners M (2013) Mild traumatic brain injury and treatment response in prolonged exposure for PTSD. J Trauma Stress 26:369-375.

Stevens JS, Kim YJ, Galatzer-Levy IR, Reddy R, Ely TD, Nemeroff CB, Hudak LA, Jovanovic T, Rothbaum BO, Ressler KJ (2017) Amygdala reactivity and anterior cingulate habituation predict posttraumatic stress disorder symptom maintenance after acute civilian trauma. Biol Psychiatry 81:1023-1029.

Stuber GD, Wise RA (2016) Lateral hypothalamic circuits for feeding and reward. Nat Neurosci 19:198-205.

Taylor S, Fedoroff IC, Koch WJ, Thordarson DS, Fecteau G, Nicki RM (2001) Posttraumatic stress disorder arising after road traffic collisions: patterns of response to cognitive-behavior therapy. J Consult Clin Psychol 69:541-551.

Tsumori T, Yokota S, Qin Y, Oka T, Yasui Y (2006) A light and electron microscopic analysis of the convergent insular cortical and amygdaloid projections to the posterior lateral hypothalamus in the rat, with special reference to cardiovascular function. Neurosci Res 56:261-269.

Ventura-Silva AP, Melo A, Ferreira AC, Carvalho MM, Campos FL, Sousa N, Pêgo JM (2013) Excitotoxic lesions in the central nucleus of the amygdala attenuate stress-induced anxiety behavior. Front Behav Neurosci 7:32.

Wahl-Schott C, Biel M (2009) HCN channels: structure, cellular regulation and physiological function. Cell Mol Life Sci 66:470-494.

Whitaker AM, Gilpin NW (2015) Blunted hypothalamo-pituitary adrenal axis response to predator odor predicts high stress reactivity. Physiol Behav 147:16-22.

Weera MM, Schreiber AL, Avegno EM, Gilpin NW (2020) The role of central amygdala corticotropin-releasing factor in predator odor stress-induced avoidance behavior and escalated alcohol drinking in rats. Neuropharmacology 166:107979.

Zhou M, Liu Z, Melin MD, Ng YH, Xu W, Südhof TC (2018) A central amygdala to zona incerta projection is required for acquisition and remote recall of conditioned fear memory. Nat Neurosci 21:1515-1519. 